This is a revised personal version of the text of the final journal article, which is made available for scholarly purposes only, in accordance with the journal's author permissions. The full citation is:

Torres D, Jiang Y, Monsalve DS \& Leeke GA (2021) Chlorine removal from the pyrolysis of urban polyolefinic waste in a semi-batch reactor, Journal of Environmental Chemical Engineering, 9 (1) Article No. 104920.

Journal of Environmental Chemical Engineering, Volume 9, Issue 1, February 2021, Article number 104920 DOI: $10.1016 /$ j.jece.2020.104920

\title{
Chlorine removal from the pyrolysis of urban polyolefinic waste in a semi-
}

\author{
batch reactor \\ D. Torres ${ }^{a^{*}}$, Y. Jiang ${ }^{\text {a }}$, D.A. Sanchez Monsalve ${ }^{b}$, G.A. Leeke ${ }^{a, c}$ \\ ${ }^{a}$ Centre for Thermal Energy Systems and Materials, School of Water, Energy and \\ Environment, Cranfield University, Cranfield MK43 OAL, UK \\ ${ }^{b}$ Recycling Technologies Ltd, Swindon SN3 4TQ, UK \\ ${ }^{c}$ School of Chemical Engineering, University of Birmingham B15 2TT, UK
}

\begin{abstract}
:
The pyrolysis of urban chlorine-containing polyolefinic plastic waste with simultaneous retention of $\mathrm{HCl}$ is investigated. Different chemical removers based on sodium, calcium and zinc bases, and different adsorbents based on alumina or zeolites were used inside the reactor or in downstream hot filters, respectively, for chlorine removal and upgrading of pyrolysis oils. Initially, polyolefin waste (POW, containing a 98.5 wt. \% polyolefins) was thermogravimetrically pyrolyzed to determine its thermal behaviour. Subsequently, chemical removers were mixed with the POW which was pyrolyzed at $480{ }^{\circ} \mathrm{C}$ in a semi-batch reactor.
\end{abstract}

\footnotetext{
${ }^{*}$ Corresponding author. E-mail address: Daniel.Torres-Gamarra@cranfield.ac.uk / dtorres@icb.csic.es (D. Torres).
} 
The adsorbents were tested separately in hot filters $\left(300 \pm 20^{\circ} \mathrm{C}\right)$ downstream of the pyrolysis reactor. After the pyrolysis, the resulting char containing the chemical removers and the absorbents in the hot filters were analysed by FTIR, CHN elemental analysis and ESEM-EDS to determine their respective chlorine contents. The highest chlorine retention was $23.8 \mathrm{wt}$ \% for chemical remover when used in direct contact with POW, while a zeolite used in the hot filter (gas streams) gave a chlorine retention of $65.6 \mathrm{wt} . \%$. The pyrolytic liquids consisted of mixtures of $\mathrm{C}_{7}-\mathrm{C}_{40}$ hydrocarbons made up of olefinic and aliphatic hydrocarbons with a very low presence of aromatics (estimated to be below 3 wt. \% by HPLC). In most cases, the chlorine removal processes resulted in waxier pyrolytic oils and with a higher degree of branching.

Keywords: pyrolysis of chlorinated plastic waste; chlorine removal; dehydrochlorination of plastic waste; polyolefinic waste treatment; hydrochloric acid removers; plastic pyrolytic oils

\section{INTRODUCTION}

It is well known that the consumption and management of plastics worldwide are not balanced at present with the emphasis on the former. This situation has generated a huge amount of plastic waste that requires the participation of more efficient technologies than mechanical recycling, which only assimilates $9 \%$ of the total amount produced according to the 2018 UN Environment report [1]. In this scenario, the pyrolysis of plastic waste is a growing alternative to balance this situation through the recovery of chemicals from plastic, which is known as "feedstock recycling". Despite the disadvantages of this technique that include high initial cost or the creation of undesirable products when treating special waste such as chlorinated or hospital, its many advantages encourage further development and 
research. As a sign of its versatility, pyrolysis permits treating "dirty", wet and mixed waste plastics generating a transportable and storable high calorific oil.

PVC and other chlorinated plastics (chlorinated polyethylene or chlorinated polyvinyl chloride) represent a challenge during the pyrolysis alone or in a mixture with polyolefinic plastics since they generate toxic and corrosive $\mathrm{HCl}$, and organochlorine compounds [2, 3]. Polyolefins (mostly polyethylene and polypropylene) account for $70 \%$ of the plastic materials used in packaging worldwide [4], and so they are the main waste used. Methods to remove chlorine from such waste include preheating or dehydrochlorination of chlorinated municipal waste, or the use of hot filters to retain the $\mathrm{HCl}$ present in the exhaust gases have been profusely investigated to reduce the chlorine content in the products [5-8]. In a similar light, co-pyrolysis of chlorinated plastics with biomass or with other plastics such as PP, LDPE, HDPE, PS or PET, is one of the most currently implemented thermal processes methods for treating PVC waste [2, 3, 7, 9-11]. Generally, the dehydrochlorination process is not altered in the co-pyrolysis with other plastics or biomass [9-11]. Co-pyrolysis reduces the processing cost by lowering the operating conditions and upgrading the oil obtained [7, 12]. However, although the mixture of waste dilutes the chlorine content to be treated or the number of organochlorine products generated, the new interactions with other heteroatoms and other polymer structures can result in new chlorinated compounds [7]. Likewise, it should be noted that although almost all of the organic chlorine is released in the form of $\mathrm{HCl}$ during the first dehydrochlorination stage, small amounts of aromatic hydrocarbons such as benzene, toluene, o-xylene or naphthalene have been detected in PVC pyrolysis [13]. Moreover, some authors have detected chlorobenzene formation at high temperatures [3].

To minimise the problems associated with the pyrolysis of chlorinated plastics, a dehydrochlorination step at low temperature $\left(350^{\circ} \mathrm{C}\right.$ and below) is carried out. Almost all of the initial chlorine content is eliminated and hard operating conditions are avoided [10, 14]. 
This first step is followed by a second high temperature pyrolysis step (up to $800{ }^{\circ} \mathrm{C}$ ) and in some cases by the use of further catalytic processes [8, 10, 15-18]. Another alternative is to dechlorinate the products by treating the pyrolytic oils and condensed chlorinated gases with catalysts or by hydrogenation at high-pressure [5, 19]. Catalysts used for catalysing the pyrolysis and reducing the formation of $\mathrm{HCl}$ or the chlorine content in products include metallic oxides and hydroxides of $\mathrm{Al}, \mathrm{Ni}, \mathrm{Fe}, \mathrm{Ca}$ or $\mathrm{Mo}$, as well as $\mathrm{FCC}$, composites or those based on zeolites or silica [12, 14-16, 20-24].

Pyrolysis gases can also be dehydrochlorinated using adsorbents or by additives in close contact with the plastic vapour in the reactor reducing both the $\mathrm{HCl}$ emission and the number of chlorinated compounds in the oil, in a process known as in situ upgrading. Alkaline $\left(\mathrm{NaHCO}_{3}, \mathrm{Na}_{2} \mathrm{CO}_{3}, \mathrm{Ca}(\mathrm{OH})_{2}, \mathrm{CaO}, \mathrm{CaCO}_{3}\right.$ and lime), oxide-based (of $\mathrm{Mg}, \mathrm{Al}, \mathrm{Si}, \mathrm{Pb}, \mathrm{Zn}, \mathrm{La}$, $\mathrm{Nd}, \mathrm{Ce}, \mathrm{Fe}$ and red mud) and other adsorbents such as lignocellulosic biomass or petrochemical residues have been used for this purpose [8, 11, 15, 18-20, 22, 25-36].

Finally, oils obtained from the thermochemical conversion of plastic waste allow its use as feedstock in petrochemicals, fuel or precursor of chemical compounds. Polyolefinic plastics have been used as feedstock to produce waxes, BTX and light olefins, whose distribution has been shown to be influenced mainly by temperature, residence time and the use of catalysts [24, 37]. Non-catalytic pyrolysis carried out at mild conditions produces a pyrolytic oil suitable to be used as fuel, especially low sulphur ones, alone or in blends with diesel, for heating and power generation applications, or lubricant oil [37-39]. In addition, these oils do not contain water improving its calorific value [39].

In this work, a batch reactor-scale approach was used to study the use of chemical removers and adsorbents in the pyrolysis of real chlorinated plastic-containing polyolefin waste (POW, 98.5 wt. \% polyolefins). Chemical removers and adsorbents were used in two different reaction configurations: in situ within the reactor in close contact with the waste, or in 
downstream hot filters, respectively. The behaviour of these materials in mixtures with pure PVC was analysed by TGA in our previous work [40], which developed a simple method to screen their performance at retaining organic chlorine. Here we evaluate this approach in a laboratory scale reactor with real plastic waste and report the effectiveness of chemical removers and adsorbents in the elimination of $\mathrm{HCl}$ generated from the pyrolysis of POW. Chlorine retention was measured by analysing chars and hot filters by Fourier transform infrared spectroscopy (FTIR) and scanning electron microscopy-energy dispersive X-ray spectroscopy (ESEM-EDS). Likewise, pyrolytic oils were characterized by FTIR, highperformance liquid chromatography (HPLC) and gas-chromatography-mass spectrometry (GC-MS).

\section{MATERIALS AND METHODS}

\subsection{Materials}

Pure poly (vinyl chloride) (Sigma Aldrich, purity > $99 \%$ ) and urban chlorinated polyolefin waste (POW; feedstock of a town in the south west of England) were used as-received, in powder and crushed forms, respectively. POW, whose non-plastic stream was separated before testing and experimentation, was composed of polyolefins $98.5 \mathrm{wt} \%$ (polyethylene (PE) 54.6 wt. \% and polypropylene (PP) 43.9 wt. \%) and PVC 1.5 wt. \%. This waste is mixed by the local collection service after classification by type of plastic, and is crushed to particles with sizes smaller than $1 \mathrm{~cm}$. Chlorine accounted for 0.96 wt. \% in the POW by analysis according to the European Standard EN 15408:2011. Three chemical removers (chemically reactive during pyrolysis and labelled as "Chem- $\mathrm{NaHCO}_{3}$ ", "Chem- $\mathrm{Na}_{2} \mathrm{CO}_{3}-\mathrm{ZnO}$ " and "Chem-CaO") and three adsorbents ("Ads- $\mathrm{Al}_{2} \mathrm{O}_{3}-1$ ", "Ads- $\mathrm{Al}_{2} \mathrm{O}_{3}-2$ " and "Ads-NaX"), the details of which can be found elsewhere [40], were characterized and used. All the adsorbents 
and the Chem- $\mathrm{Na}_{2} \mathrm{CO}_{3}-\mathrm{ZnO}$ chemical remover were compacted by extrusion-spheronization to 1-3 mm particles in order to be packed in a fixed bed for use as hot filters.

The apparent densities of crushed POW as well as adsorbents and chemical removers (compacted and powders, respectively), determined from the weight and the volume occupied by the sample in a graduated cylinder, were: crushed POW $=380.3 \mathrm{~kg} / \mathrm{m}^{3}$, Chem- $\mathrm{NaHCO}$

powder $=768.9 \mathrm{~kg} / \mathrm{m}^{3}$, Chem $-\mathrm{Na}_{2} \mathrm{CO}_{3}-\mathrm{ZnO}$ powder $=692.3 \mathrm{~kg} / \mathrm{m}^{3}$, Chem- $\mathrm{Na}_{2} \mathrm{CO}_{3}-\mathrm{ZnO}$ compacts $=744.4 \mathrm{~kg} / \mathrm{m}^{3}$, Chem $-\mathrm{CaO}$ powder $=654.5 \mathrm{~kg} / \mathrm{m}^{3}$, Ads $-\mathrm{Al}_{2} \mathrm{O}_{3}-1$ compacts $=865.4$ $\mathrm{kg} / \mathrm{m}^{3}$, Ads $-\mathrm{Al}_{2} \mathrm{O}_{3}-2$ compacts $=844.5 \mathrm{~kg} / \mathrm{m}^{3}$ and Ads $-\mathrm{NaX}$ compacts $=779.4 \mathrm{~kg} / \mathrm{m}^{3}$.

\subsection{Thermobalance tests}

A Perkin Elmer TGA $8000^{\mathrm{TM}}$ thermogravimetric analyser was used to study the pyrolysis of PVC and POW. Thermogravimetric profiles were obtained from a sample amount of $20 \mathrm{mg}$ and using $40 \mathrm{ml} \mathrm{min}{ }^{-1}$ of $\mathrm{N}_{2}$ as an inert atmosphere for pyrolysis. The temperature program consisted of heating the sample $\left(10^{\circ} \mathrm{C} / \mathrm{min}\right)$ from room temperature to $750{ }^{\circ} \mathrm{C}$ followed by a stabilization stage at this temperature for 2 min. 3 repetitions were performed for each material to obtain reproducible results.

\subsection{Reaction configurations and pyrolysis of POW}

The pyrolysis of POW was carried out in a stirred semi-batch reactor $(250 \mathrm{ml}$ Parr reactor, Hastelloy C-2000 alloy) as described in Figure 1. Although the pyrolysis occurs inside the reactor, a continuous stream of $\mathrm{N}_{2}$ drags the gaseous products generated out of it. Reaction continues until all the pyrolyzable fraction has reacted remaining only the char. Two configurations were used depending mainly on the type of the material tested. Chemical removers (Chem- $\mathrm{NaHCO}_{3}, \mathrm{Chem}-\mathrm{Na}_{2} \mathrm{CO}_{3}-\mathrm{ZnO}$ and $\left.\mathrm{Chem}-\mathrm{CaO}\right)$ were added to the polyolefin waste in the reactor at the beginning of the experiment (Figure 1a), while adsorbents (Ads- 
$\mathrm{Al}_{2} \mathrm{O}_{3}-1$, Ads- $\mathrm{Al}_{2} \mathrm{O}_{3}-2$ and Ads-NaX) were packed in a hot filter at the reactor outlet (Figure 1b). The chemical remover Chem- $\mathrm{Na}_{2} \mathrm{CO}_{3}-\mathrm{ZnO}$ was also tested as a hot filter. Hot filters were prepared filling a 3/4 inch Swagelok stainless steel tube $25 \mathrm{~cm}$ long with the corresponding compacted adsorbent. The hot filter was duly insulated to maintain the temperature in the range of $300 \pm 20^{\circ} \mathrm{C}$ and it was housed in the immediate outlet of the reactor. After the reaction system (with or without the hot filter), the product passes through a condenser $\left(0^{\circ} \mathrm{C}\right)$ and is collected in a flask reactor immersed in an ice bath. Another condenser $\left(0{ }^{\circ} \mathrm{C}\right)$ is located after the flask to avoid the loss of condensable products at room temperature. The exhaust gases are bubbled through $\mathrm{KOH}$ solution to avoid $\mathrm{HCl}$ emissions. In a typical run, $20 \mathrm{~g}$ of POW are placed in the reactor together with $15 \mathrm{~g}$ of chemical remover or alone in case of using adsorbents, in which $15 \mathrm{~g}$ of adsorbents are packed in the hot filter. The pyrolysis is carried out at $480 \pm 15{ }^{\circ} \mathrm{C}$ at atmospheric pressure up to a maximum of $3 \mathrm{~h}$ using $120 \mathrm{ml} \mathrm{min}{ }^{-1}$ of $\mathrm{N}_{2}$ as the inert carrier gas. The reactor and contents were heated from ambient with a heating ramp of $10{ }^{\circ} \mathrm{C} \mathrm{min}^{-1}$. Before heating, the reactor is purged and subjected to $10 \mathrm{bar}$ pressure test with $\mathrm{N}_{2}$.

a)

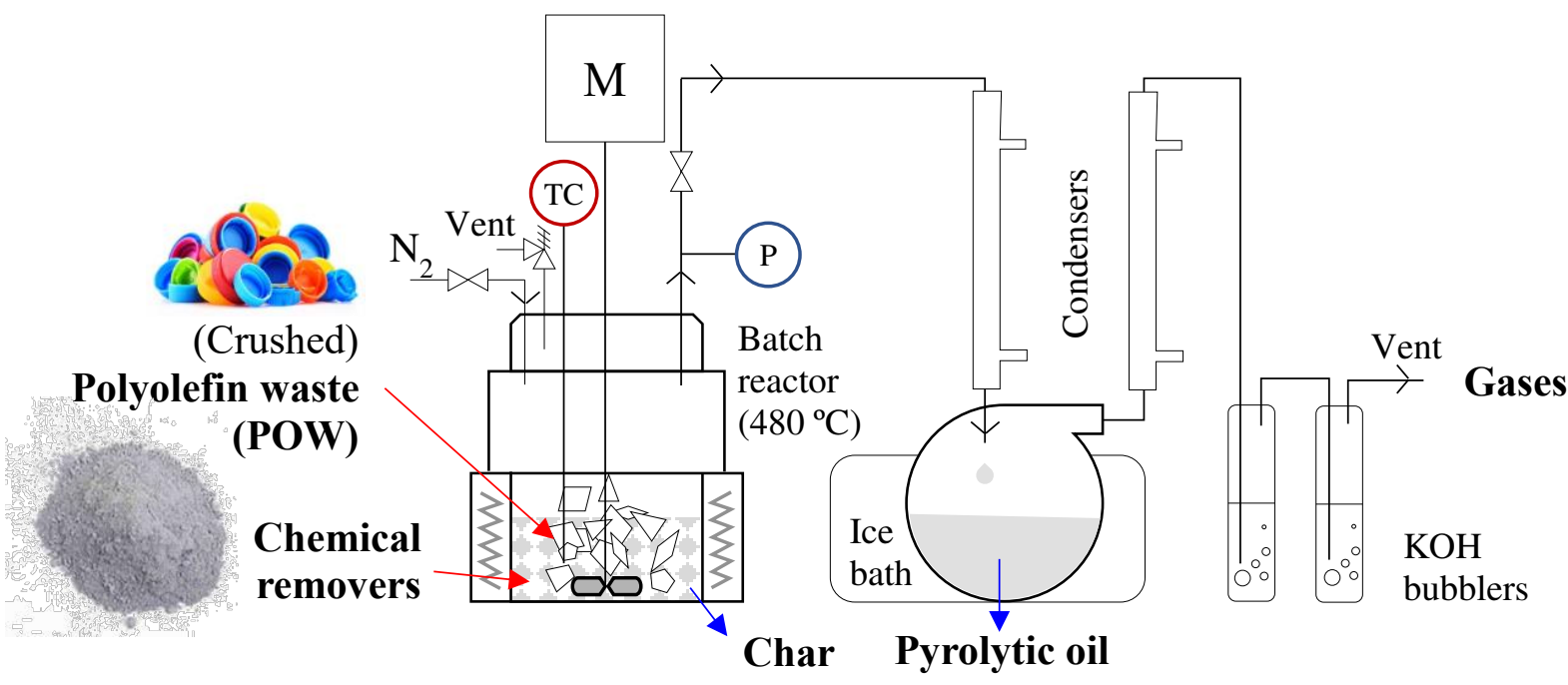

b) 


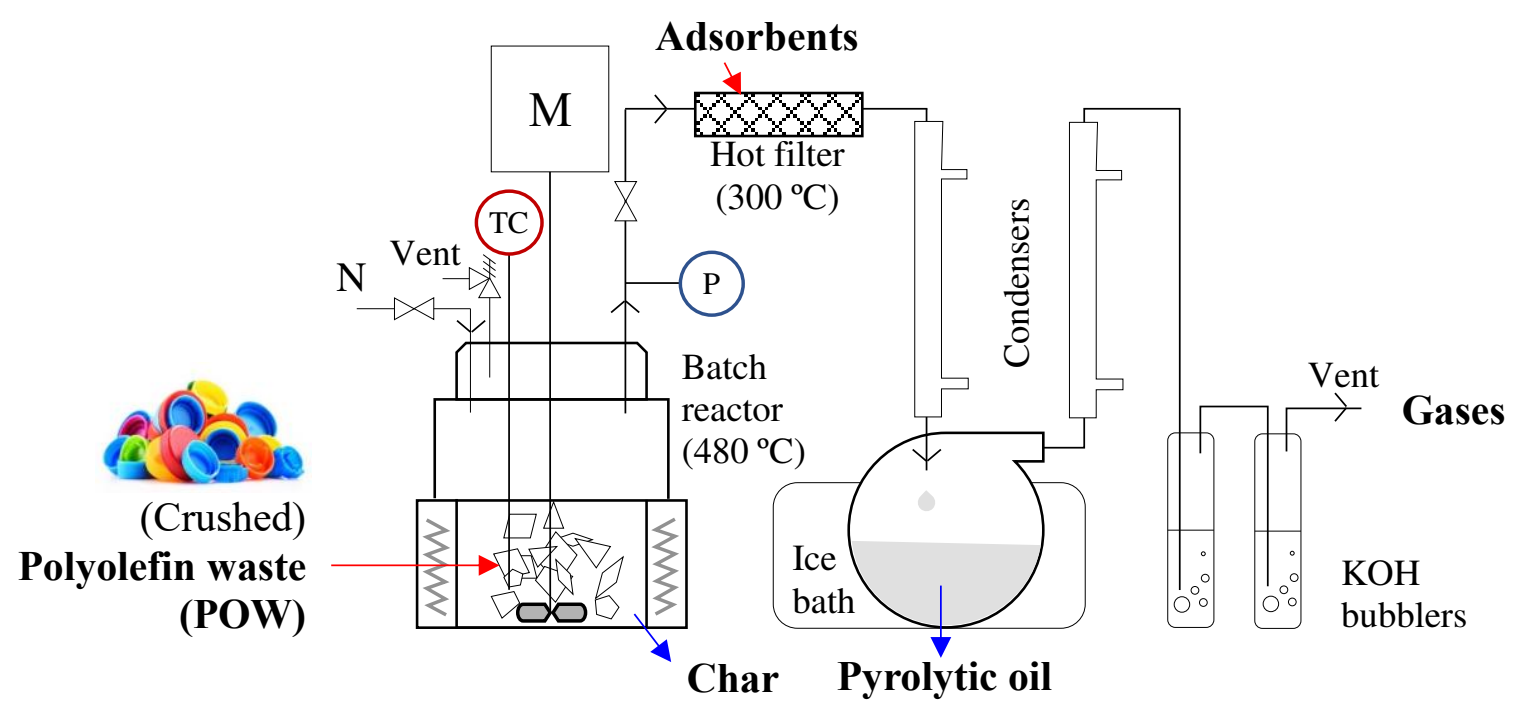

Figure 1 Set-up of the pyrolysis process. a) configuration to test chemical removers mixed with POW inside the reactor; b) configuration to test adsorbents as hot filters.

\subsection{Characterization techniques}

The appearance of chars and hot-filters after use was determined by an environmental scanning electron microscopy (ESEM, FEI Philips XL30). This equipment allows the examination of chemical composition by a coupled EDS analyser (Oxford Instruments, XMax detector). Samples, without further treatment, were adhered to a carbon conducting tape mounted on an aluminium stud for viewing. The spectra were collected from large areas (5 at least) per sample. Using X-ray maps, the element spatial distributions over selected areas of the surface of adsorbents after use as a hot filter were determined. For an adequate elemental quantification, EDS accuracy was adjusted by subtraction of the contribution of the conductive tab, measurement of a minimum of 5 different large areas of each sample, correction with $\mathrm{CHN}$ elemental analysis data and verification with standards of known composition.

CHN elemental analysis was performed using a Perkin-Elmer CHN Elemental Analyzer by combustion of the samples at $900{ }^{\circ} \mathrm{C}$, separation of $\mathrm{CO}_{2}, \mathrm{H}_{2} \mathrm{O}$ and $\mathrm{N}_{2}$ by frontal 
chromatography and quantification by a thermal conductivity detector (TCD). Samples were dried at $105^{\circ} \mathrm{C}$ and

$0.020 \mathrm{~g}$ packed in aluminium-foil capsules.

The FTIR transmittance spectra of solids and pyrolytic oils were determined using a SHIMADZU IRTracer-100 spectrophotometer using the attenuated total reflection (ATR) technique. Transmittance was measure in the range of 500 and $4000 \mathrm{~cm}^{-1}$ with 15 scans at a resolution of $4 \mathrm{~cm}^{-1}$.

The chlorine retention ( $\mathrm{Cl}$ retention) obtained by a material in the POW pyrolysis was calculated as the percentage of chlorine content loss between that calculated in the char (or in the filter after use in the case of use hot filters) by SEM-EDS and CHN elemental analysis and that in the as-received POW:

Cl retention $(w t . \%)=\left(M_{C l} / M_{C l \_P O W}\right) \times 100$

Where $M_{C l \_P O W}$ and $M_{C l}$ correspond to the respective masses of $\mathrm{Cl}$ in the POW and the char (or hot filter after use if this configuration is used). In the case of the hot filter configuration, the amount of chlorine not released from the starting POW and which remains in the composition of the char located in the reactor is not considered.

The GC-MS data were generated using a Perkin Elmer Clarus 680 gas chromatography unit attached to a Clarus SQ 8 S mass spectrometer. Samples were injected onto an Elite-5MS 30meter column with a 0.25 micrometre 1,4-bis(dimethylsiloxy)phenylene dimethyl polysiloxane liner. The assignment of peaks was carried out by comparison with linear alkane and single ring aromatic standards, as well as the use of the mass spectra data, and by comparison to the Perkin Elmer NIST mass spectrum library.

HPLC spectra of pyrolytic oils were acquired using an HPLC system consisting of a solvent delivery pump and a Refractive Index Detector. The column used was a ZORBAX NH2 (250 $\mathrm{mm} \times 4.6 \mathrm{~mm}$ ID, $5 \mu \mathrm{m}$ ) from Agilent Technologies. The mobile phase was n-heptane (HPLC 


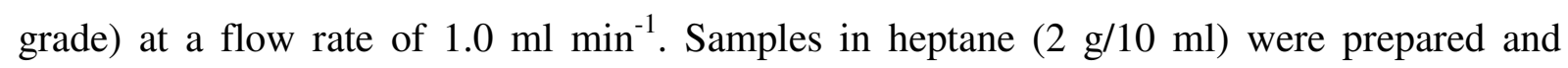
analysed according to the ASTM D6379-11 method.

\section{RESULTS}

\subsection{Thermogravimetric pyrolysis of POW and characterization of the resulting char}

TGA and DTG of POW were performed to assess its thermal behaviour (Figure 2a-b). The pyrolysis of pure PVC was investigated as the reference in order to compare the main mass losses. During the thermal decomposition of PVC, the first mass loss of around 65.1 wt. \% (starting at $250{ }^{\circ} \mathrm{C}$ ) is attributed to the $\mathrm{HCl}$ released, the second mass loss (starting at $410{ }^{\circ} \mathrm{C}$ ) corresponds to the degradation of the dehydrochlorinated organic residues [7]. POW also showed two losses but their nature is more complex (PE 54.6 wt. \%; PP $\sim 43.9$ wt. \% and PVC 1.5 wt. \%). However, the organic chlorine content would be below 5.0 wt. \% (expressed as $\mathrm{HCl}$ ) if the first mass loss recorded is considered. In any case, both materials formed a char-like material after pyrolysis (around 4.5-6.1 wt. \%), which could contain chlorine derivatives. In the case of PVC, this first mass loss was higher than that associated with the $\mathrm{HCl}$ content in PVC (58.4 wt. \%) so the presence of chlorine compounds in the char should be very low.

The chlorine residues in the pyrolytic chars were evaluated by FTIR, a technique that has previously proven effective in the assessment of remaining organic chlorine [40]. In light of this, pure PVC and the char obtained from the POW pyrolysis at $480{ }^{\circ} \mathrm{C}$ were analysed by FTIR (Figure 2c-d) to verify the absence of $\mathrm{C}-\mathrm{Cl}$ bond signals. It should be noted that this temperature is sufficient to guarantee the almost complete dehydrochlorination of the PVC [41]. The analysis of POW char serves as a basis for comparing samples obtained in the batch reactor as char is known to act as a chlorine-remover material. Organic chlorine in PVC presents adsorption bands at 685 and $606 \mathrm{~cm}^{-1}$ due to $\mathrm{C}-\mathrm{Cl}$ stretching in $-\mathrm{CHCl}-$ functional 
groups. For these same groups, bands at 2816 and $2968 \mathrm{~cm}^{-1}$, and 1329 and $1244 \mathrm{~cm}^{-1}$, correspond to $\mathrm{C}-\mathrm{H}$ stretching and bending vibrations, respectively [41].

POW chars did not show the presence of bands associated with the $-\mathrm{CHCl}-$ groups or with any of its bonds as a result of the dehydrochlorination process. After pyrolysis, the band at $1634 \mathrm{~cm}^{-1}$ and the shoulder around $1600 \mathrm{~cm}^{-1}$ found in POW char were attributed to the $\mathrm{C}=\mathrm{C}-$ vibration in aliphatic and aromatic rings. On the other hand, oxygen-containing groups were presented in the POW char: $-\mathrm{OH}$ stretching and bending vibrations appeared as a broad band centred at $1410 \mathrm{~cm}^{-1}$. New small peaks around 872 and $752 \mathrm{~cm}^{-1}$ were assigned to the $=\mathrm{C}-\mathrm{H}$ out of plane vibration of the aromatic rings, which is attributed to the formation of small quantities of aromatic pyrolysis products [42, 43]. Pyrolysis of PP and PVC has been shown to obtain products containing aromatics [44].

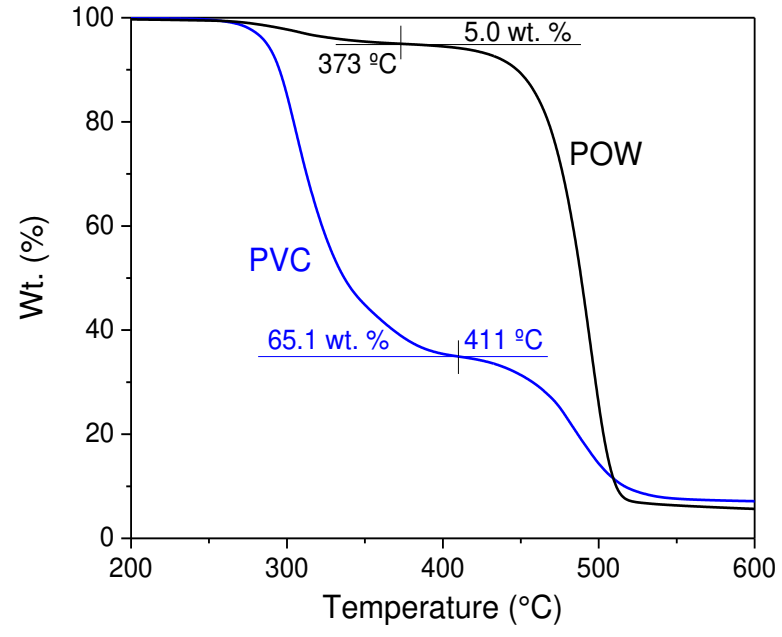

a)

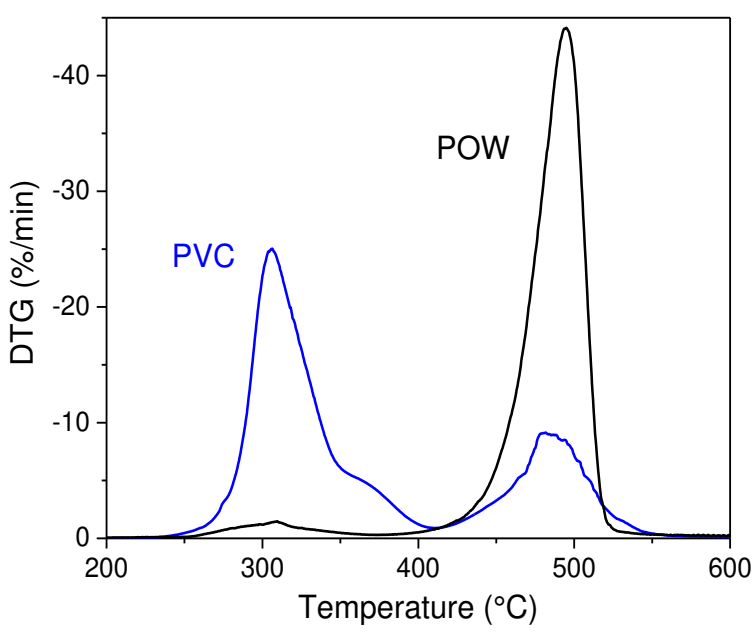

b) 


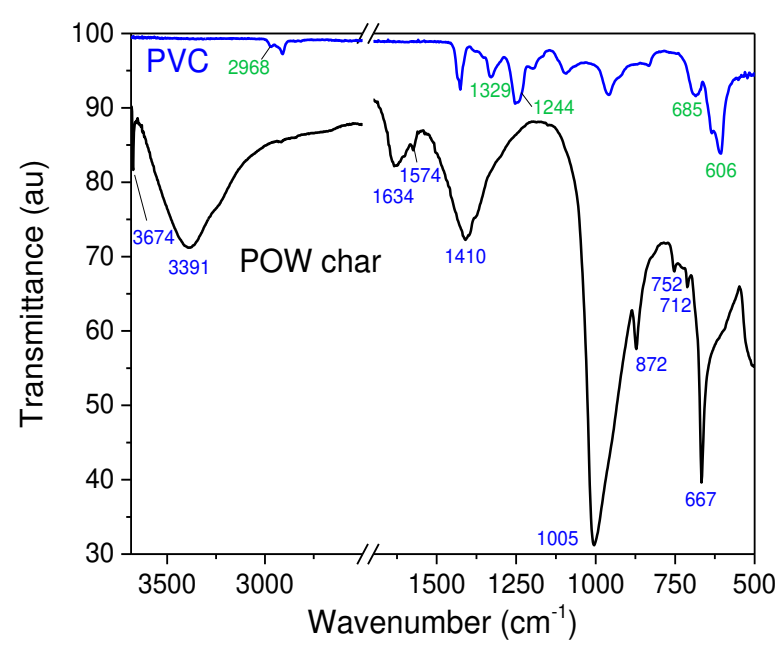

c)

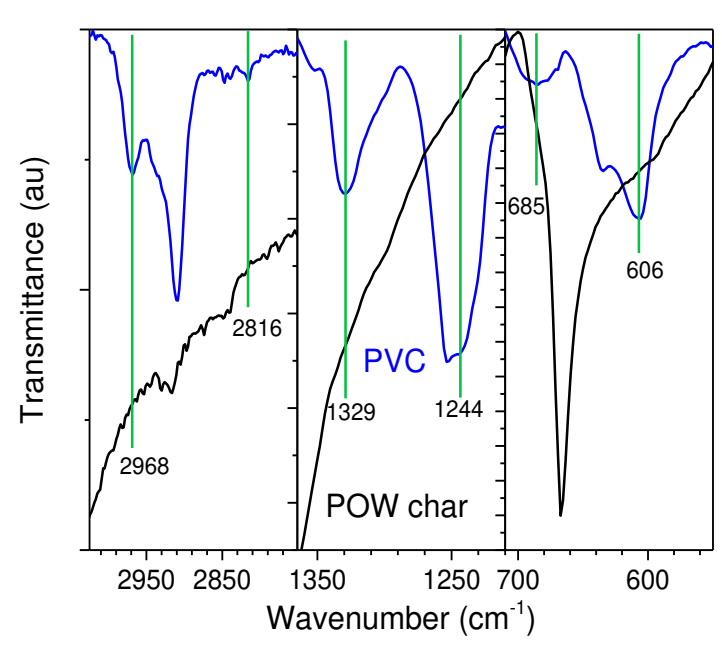

d)

Figure 2 a) TGA and b) DTG profiles of POW and pure PVC in $\mathrm{N}_{2}$ atmosphere at a heating rate of $10{ }^{\circ} \mathrm{C} / \mathrm{min}$. c) FTIR spectra of POW pyrolyzed to $480{ }^{\circ} \mathrm{C}$ and pure PVC. d) Zones of bands associated with $\mathrm{C}-\mathrm{H}$ and $\mathrm{C}-\mathrm{Cl}$ stretching in the $-\mathrm{CHCl}-$ groups for $\mathrm{POW}$ char and pure PVC.

Finally, the weight composition of POW char was measured by ESEM-EDS and CHN elemental analysis as shown in Table 1 . The char showed the presence of a wide variety of elements in addition to $\mathrm{C}(48.3 \%), \mathrm{H}(3.4 \%)$ and $\mathrm{Cl}(1.0 \%)$, the structural components of the bare plastics of POW (PE, PP and PVC). The presence of $\mathrm{Si}, \mathrm{Ca}, \mathrm{Ti}, \mathrm{Mg}, \mathrm{Fe}, \mathrm{Al}, \mathrm{Na}, \mathrm{Zn}$, $\mathrm{S}, \mathrm{Cr}, \mathrm{Cu}, \mathrm{P}$ and $\mathrm{K}$, which represent $20 \%$ of the char weight, correspond to additives used in the plastic industry such as functional additives, colorants, fillers or reinforcements [45]. Moreover, stable oxides of these foreign elements are the reason for the high oxygen content measured in the char (27 wt. \%), which is in line with what was previously reported for chars from the pyrolysis of urban plastic waste $[24,46]$. Cho et al. measured an inorganic content in the char from mixed plastic wastes higher than 75 wt. \% [24]. Although the dehydrochlorination process can be completed at higher temperatures, the char analysed was 
obtained at $480{ }^{\circ} \mathrm{C}$, and with a mass of 1.0 wt. \% accounts for 4.3 wt. $\%$ of the chlorine retention without the use of a chemical remover.

Table 1. Elemental composition of char from POW pyrolysis measured by ESEM-EDS and CHN elemental analysis.

\begin{tabular}{|c|c|c|}
\hline & Element & Wt. \% \\
\hline \multirow{4}{*}{ CHN E.A. } & $\mathrm{C}$ & 48.3 \\
\cline { 2 - 3 } & $\mathrm{H}$ & 3.4 \\
\cline { 2 - 3 } & $\mathrm{N}$ & 0.3 \\
\hline \multirow{5}{*}{ ESEM-EDS } & $\mathrm{O}$ & 27.0 \\
\cline { 2 - 3 } & $\mathrm{Si}$ & 5.9 \\
\cline { 2 - 3 } & $\mathrm{Ca}$ & 4.4 \\
\cline { 2 - 3 } & $\mathrm{Ti}$ & 3.6 \\
\cline { 2 - 3 } & $\mathrm{Mg}$ & 2.9 \\
\cline { 2 - 3 } & $\mathrm{Fe}$ & 1.4 \\
\cline { 2 - 3 } & $\mathrm{Cl}$ & 1.0 \\
\cline { 2 - 3 } & $\mathrm{Na}$ & 0.7 \\
\cline { 2 - 3 } & $\mathrm{Zn}$ & 0.3 \\
\cline { 2 - 3 } & $\mathrm{S}$ & 0.3 \\
\cline { 2 - 3 } & $\mathrm{Cr}$ & 0.2 \\
\cline { 2 - 3 } & $\mathrm{Cu}$ & 0.2 \\
\cline { 2 - 3 } & $\mathrm{P}$ & 0.1 \\
\cline { 2 - 3 } & $\mathrm{K}$ & 0.1 \\
\hline
\end{tabular}

\subsection{Pyrolysis of POW in the presence of chemical removers}

Chemical removers (Chem-NaHCO 3 , Chem- $\mathrm{Na}_{2} \mathrm{CO}_{3}-\mathrm{ZnO}$ and $\left.\mathrm{Chem}-\mathrm{CaO}\right)$ were mixed with POW in a ratio of 3:4 wt./wt. and their mixtures were pyrolyzed in the batch reactor at $480{ }^{\circ} \mathrm{C}$. During pyrolysis, organic chlorine in the plastic waste is released as $\mathrm{HCl}$ and reacts with the bases present in the chemical removers studied as follows:

$\mathrm{ZnO}(\mathrm{s})+2 \mathrm{HCl}(\mathrm{g}) \rightarrow \mathrm{ZnCl}_{2}(\mathrm{~s})+\mathrm{H}_{2} \mathrm{O}(\mathrm{g})$

$\mathrm{Na}_{2} \mathrm{CO}_{3}(\mathrm{~s})+2 \mathrm{HCl}(\mathrm{g}) \rightarrow 2 \mathrm{NaCl}(\mathrm{s})+\mathrm{H}_{2} \mathrm{O}(\mathrm{g})+\mathrm{CO}_{2}(\mathrm{~g})$

$\mathrm{CaO}(\mathrm{s})+2 \mathrm{HCl}(\mathrm{g}) \rightarrow \mathrm{CaCl}_{2}(\mathrm{~s})+\mathrm{H}_{2} \mathrm{O}(\mathrm{g})$

A blank experiment with POW was also performed where no hot filter is placed in the gas exit. After experiments with chemical remover, char (mixed with the chemical remover 
residue in a char/remover ratio $\sim 10 / 90$ wt./wt.) and condensed pyrolytic oils were collected and their masses obtained are given in Table 2. Chem- $\mathrm{NaHCO}_{3}$ contains $\mathrm{NaHCO}_{3}$ which initially decomposes into $\mathrm{Na}_{2} \mathrm{CO}_{3}$ at temperatures below the PVC dehydrochlorination stage [40], so the reaction of $\mathrm{NaHCO}_{3}$ with $\mathrm{HCl}$ does not occur. Additionally, the formed salts will remain in the char since the pyrolysis of chlorinated plastic in this study takes place at $480{ }^{\circ} \mathrm{C}$. Pyrolysis involving the participation of a chemical remover generates a decrease in liquid yield $\left(Y_{O i l}\right)$, except for the case of Chem- $\mathrm{NaHCO}_{3}$, which showed a slight increase.

Table 2. Mass of POW, chemical removers mixed with the POW and products obtained after pyrolysis at $480^{\circ} \mathrm{C}$.

\begin{tabular}{|c|c|c|c|c|c|c|c|c|}
\hline & \multicolumn{2}{|c|}{ Initial } & \multicolumn{6}{|c|}{ After pyrolysis } \\
\hline & $\begin{array}{c}\text { POW } \\
(\mathrm{g})\end{array}$ & $\begin{array}{l}\text { Remover } \\
(\mathrm{g})\end{array}$ & $\begin{array}{c}\text { Char }^{\mathrm{a}} \\
(\mathrm{g})\end{array}$ & $\begin{array}{c}\text { wt. loss }{ }^{b} \\
(\%)\end{array}$ & $\begin{array}{l}\text { Oil } \\
(\mathrm{g})\end{array}$ & $\begin{array}{c}Y_{O i l}{ }^{c} \\
\text { (wt. \%) }\end{array}$ & $\begin{array}{c}\text { Oil } \\
(\mathrm{ml})\end{array}$ & $\begin{array}{c}\text { Oil } \\
\text { (state) }\end{array}$ \\
\hline POW (blank) & 19.9 & - & 0.7 & 96.5 & 14.0 & 70.4 & 16.0 & Liq. \\
\hline+ Chem-NaHCO ${ }_{3}$ & 20.0 & 15.1 & 1.0 & 95.0 & 15.1 & 75.5 & 17.5 & Sol. \\
\hline + Chem-CaO & 20.0 & 15.0 & 1.6 & 92.0 & 13.2 & 66.0 & 15.0 & Sol. \\
\hline+ Chem- $\mathrm{Na}_{2} \mathrm{CO}_{3}-\mathrm{ZnO}$ & 20.0 & 15.1 & 1.4 & 93.0 & 12.3 & 61.5 & 13.0 & Sol. \\
\hline
\end{tabular}

$\mathrm{a}=$ Char discounting the chemical remover residue estimated by TGA [40]. $\mathrm{b}=$ POW weight loss. $\mathrm{c}=Y_{\text {Oil }}($ wt. \% $)=($ mass of oil produced / initial mass of POW) $x 100$.

After pyrolysis, solid residues composed of the homogenous mixture of char and the chemical remover were analysed by FTIR and ESEM-EDS. In Figure 3 images of char obtained from the pyrolysis of POW only are shown, while micrographs of chars using chemical removers are shown in Figure 4. The presence of fibers from reinforced plastics and metals (bright spots) is evident in some images. Images of chemical removers prior to use can be found in our previous work [40]. Chem- $\mathrm{CaO}$ and $\mathrm{Chem}-\mathrm{NaHCO}_{3}$ contained activated carbon (see examples in circles in Figure $4 \mathrm{a}$ and $4 \mathrm{~b}$ ), which was easily distinguishable by ESEM. Chemical removers presented differences due to the formation of chlorine salts (confirmed by ESEM-EDS). 


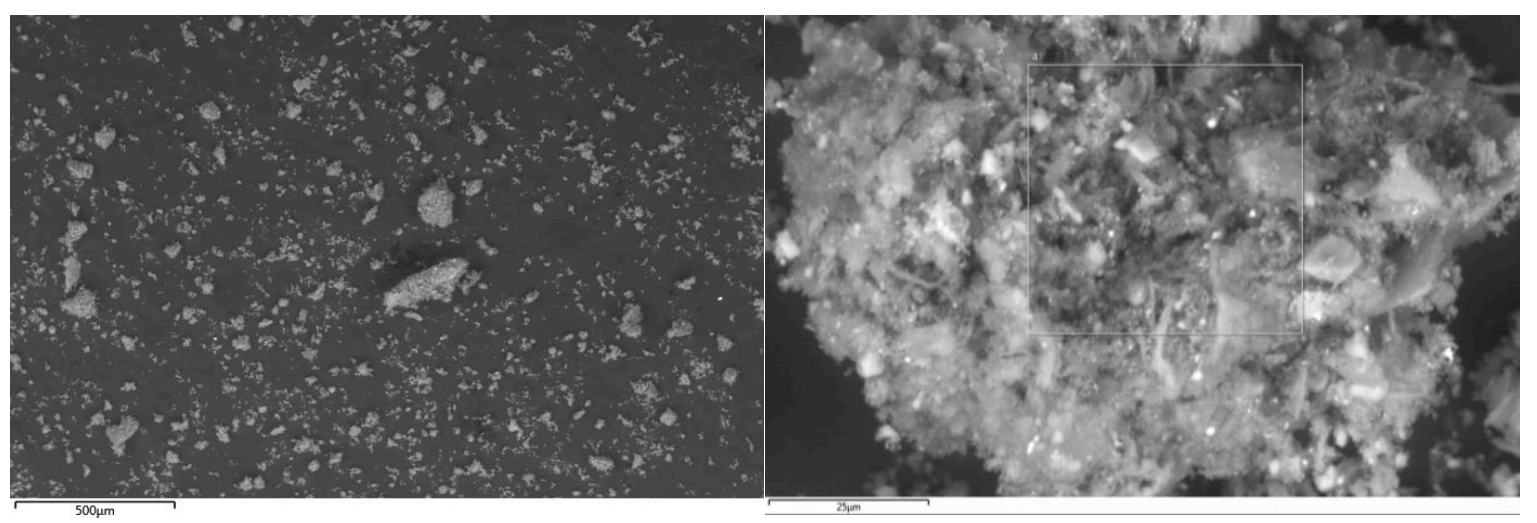

Figure 3 ESEM images of the char obtained from the POW pyrolysis at $480{ }^{\circ} \mathrm{C}$ and $3 \mathrm{~h}$. High magnification ESEM image (right) shows an example of a rectangular area used for chlorine determination by EDS.

a)

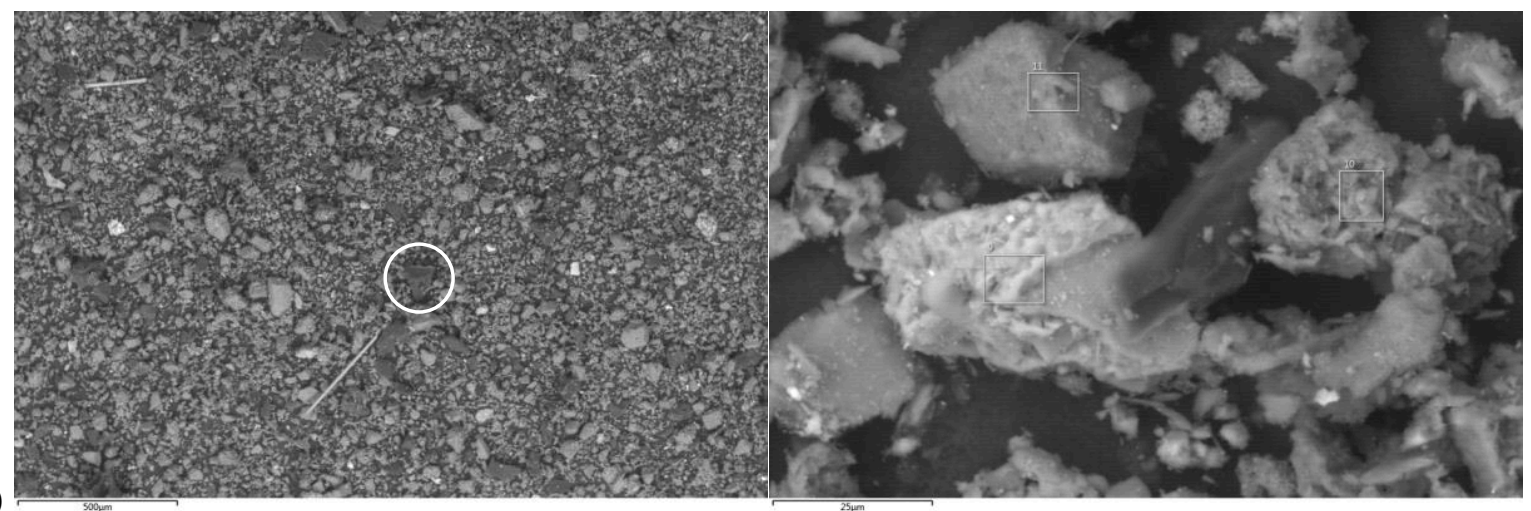

b)

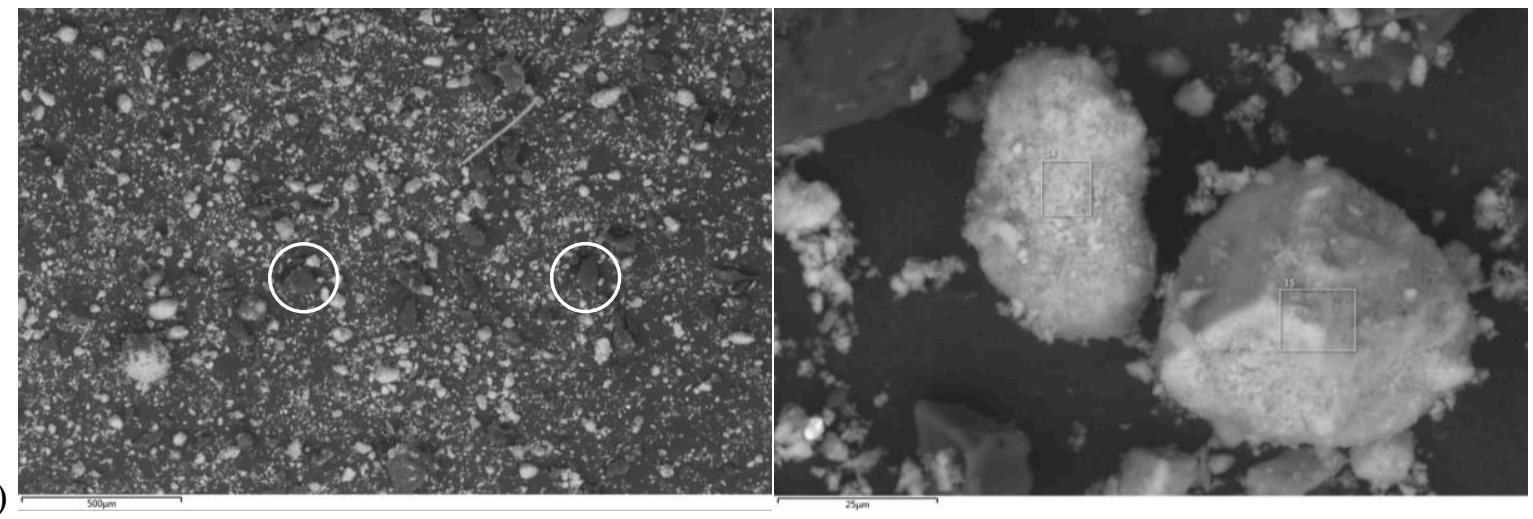


c)

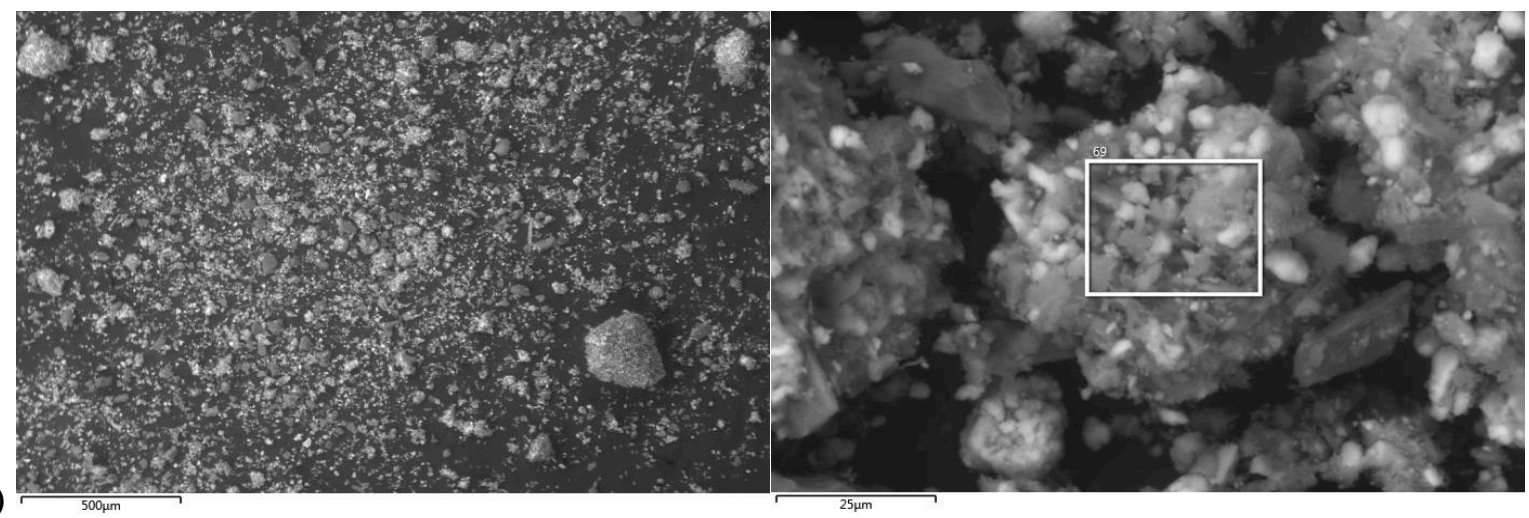

Figure 4 ESEM images of a) $\mathrm{POW}+\mathrm{Chem}-\mathrm{NaHCO}_{3}$, b) $\mathrm{POW}+\mathrm{Chem}-\mathrm{CaO}$, and c) $\mathrm{POW}+$ Chem- $\mathrm{Na}_{2} \mathrm{CO}_{3}-\mathrm{ZnO}$ mixtures after pyrolysis in batch reactor at $480{ }^{\circ} \mathrm{C}$ for $3 \mathrm{~h}$. High magnification ESEM images show examples of rectangular areas used in the chlorine determination by EDS.

Chlorine retentions (wt. \%) of the chemical removers were estimated using the ESEM-EDS and CHN elemental analysis data and are listed in Table 3. The initial chlorine content in POW accounts for 0.85 wt. \%. Pure PVC pyrolysis was studied in thermobalance in our previous study [40], and the effectiveness of the chemical removers at the lab-scale batch experiments showed similar trends with Chem- $\mathrm{Na}_{2} \mathrm{CO}_{3}-\mathrm{ZnO}(23.8 \%)>$ Chem- $\mathrm{CaO}(14.9 \%)$ $>$ Chem- $\mathrm{NaHCO}_{3}(6.7 \%)$, demonstrating the effectiveness of the thermogravimetric evaluation method. However, a significant part of inorganic chlorine is fixed in the char as can be observed by the chlorine retention obtained when no chemical remover is used (4.3 $\%)$. It should be noted that residual chlorine in the char could be avoided by pyrolyzing the POW at a higher temperature with the consequent energy cost. On the other hand, chemical removers resulted in active bases remaining in the char (as will be shown later by FTIR of the char generated) as a consequence of both an inefficient contact with $\mathrm{HCl}$ in the reactor and a low amount of chlorine in the chlorinated plastic waste. In comparison to the literature, some bases exhibited higher chlorine retention when in contact with pyrolysis gases and when used at the optimum temperature. For example, $\mathrm{CaO}$ adsorbent exhibited the highest $\mathrm{HCl}$ capture 
capacity at $550{ }^{\circ} \mathrm{C}[35]$. Lopez-Urionabarrenechea et al. used $\mathrm{CaCO}_{3}$ powder (purity grade > $98.5 \%$ ) as a $\mathrm{Cl}$ chemical remover (mixed with the plastic feedstock) in the pyrolysis of a PVC-containing plastic mixture (PE, PP, PS, PET and PVC, Cl content of 1.1 wt. \%) and they reported a $\mathrm{Cl}$ retention of 7.3 wt. \% in the char according to Equation 1 ( 0.2 wt. \% for conventional pyrolysis) [18]. Same authors also tested ZSM-5 zeolite as the catalyst for the pyrolysis of the same plastic mixture, and char retained 0.4 wt. $\%$ of $\mathrm{Cl}, 4$ times that obtained by conventional thermal pyrolysis and similar solid yields (3.2 and $3.0 \mathrm{wt}$. \% for catalytic and thermal processes, respectively) [14]. Recently, Fekhar et al. tested two mixtures of catalysts and bases in different ratios: $\mathrm{Ni} / \mathrm{ZSM}-5+\mathrm{red} \operatorname{mud}+\mathrm{Ca}(\mathrm{OH})_{2}$ and $\mathrm{Ni} / \mathrm{SAPO}-11+$ red mud + $\mathrm{Ca}(\mathrm{OH})_{2}$, for the pyrolysis of municipal plastic waste, and they stated that formulations with red mud and $\mathrm{Ca}(\mathrm{OH})_{2}$ as the main components retained the highest chlorine contents in the chars (with a maximum of up to 20 times more than in the char obtained without catalyst) [23].

Table 3. Chlorine retention calculated as the percentage of chlorine content loss between that calculated in the char and that in the as-received POW according to Equation 1.

\begin{tabular}{|c|c|c|}
\hline & $\begin{array}{l}\text { Residue }^{*} \\
\text { (g) }\end{array}$ & $\begin{array}{l}\mathrm{Cl} \text { retention }{ }^{*} \\
\text { (wt. \%) }\end{array}$ \\
\hline POW & 0.73 & $4.3^{\mathrm{a}}$ \\
\hline $\mathrm{POW}+\mathrm{Chem}-\mathrm{NaHCO}_{3}$ & 11.02 & 6.7 \\
\hline $\mathrm{POW}+\mathrm{Chem}-\mathrm{CaO}$ & 13.62 & 14.9 \\
\hline $\mathrm{POW}+\mathrm{Chem}-\mathrm{Na}_{2} \mathrm{CO}_{3}-\mathrm{ZnO}$ & 15.10 & 23.8 \\
\hline
\end{tabular}

$*$ Residue $=$ char + chemical remover residue (when used). $*=$ Chlorine measured by ESEM-EDS for chars (including the chemical remover residue) obtained from the pyrolysis of POW at $480{ }^{\circ} \mathrm{C}$ in the presence of different chemical removers. $\mathrm{a}=$ without the addition of chemical remover.

Chars generated from the pyrolysis of POW and POW + chemical remover mixtures at $480{ }^{\circ} \mathrm{C}$ were analysed by FTIR. Figure 5a shows the FTIR spectra of chemical removers and 1:1 mixtures, before and after pyrolysis at $480{ }^{\circ} \mathrm{C}$, respectively, while Figure $5 \mathrm{~b}$ shows a zoom of 
the $710-550 \mathrm{~cm}^{-1}$ region. At first glance, the signals of the $\mathrm{C}-\mathrm{Cl}$ and $\mathrm{C}-\mathrm{H}$ bonds of the $\mathrm{CHCl}$ - functional groups in organic chlorine were not present in the FTIR spectra. The POWonly char contained elements (listed in Table 1) which can form inorganic salts with the chlorine from the $\mathrm{HCl}$ released. The identification of these chlorine salts, as well those obtained from tests involving the participation of the active bases contained in the chemical removers, could be identified by this technique after identifying their representative bands. This identification method can be found elsewhere [40]. Chemical removers before use ("Fresh" in Figure 5a) showed the expected contributions in the spectra from their different compositions, including adsorption bands of $\mathrm{NaHCO}_{3}$ [47] in Chem- $\mathrm{NaHCO}_{3}, \mathrm{CaO}$ [48] in Chem- $\mathrm{CaO}$ and $\mathrm{Na}_{2} \mathrm{CO}_{3}$, and $\mathrm{ZnO}, \gamma-\mathrm{Al}_{2} \mathrm{O}_{3}$ and $\mathrm{SiO}_{2}[47,49-55]$ in Chem- $\mathrm{Na}_{2} \mathrm{CO}_{3}-\mathrm{ZnO}$.

After the pyrolysis of POW and 1:1 mixtures ("Pyrolyzed" in Figure 5b), bases of the chemical removers are evident in the FTIR spectra, except for the case of Chem- $\mathrm{NaHCO}_{3}$, whose active phase was thermally transformed into $\mathrm{Na}_{2} \mathrm{CO}_{3}$, also evident in the corresponding FT-IR spectra. The spectra of the pyrolyzed mixtures containing Chem- $\mathrm{NaHCO}_{3}$ and Chem$\mathrm{Na}_{2} \mathrm{CO}_{3}-\mathrm{ZnO}$ share the bands associated with $\mathrm{Na}_{2} \mathrm{CO}_{3}$. Clearly, the bands of the bases are present in the chars of the mixtures after the pyrolysis indicating that the bases could still react with more $\mathrm{HCl}$. Additionally, the formation of the respective chlorinated salts is small since the chlorine content in POW is initially low. Despite the retention of 14.9 wt. \% of chlorine in the case of Chem-CaO (see Table 3), for example, the corresponding chlorine salt $\left(\mathrm{CaCl}_{2}\right)$ would only correspond to $0.2-0.3$ wt. $\%$ of char. Additionally, $\mathrm{NaCl}$ absorbs infrared light outside the $4000-500 \mathrm{~cm}^{-1}$ region so it is absent in the FTIR spectra shown. The wavenumber of the vibrations for the $\mathrm{Ca}-\mathrm{Cl}$ bond in $\mathrm{CaCl}_{2}$ and the $\mathrm{Zn}-\mathrm{Cl}$ bond in $\mathrm{ZnCl}_{2}$ are marked in Figure 5a; however, they are overshadowed by the POW char profile. 

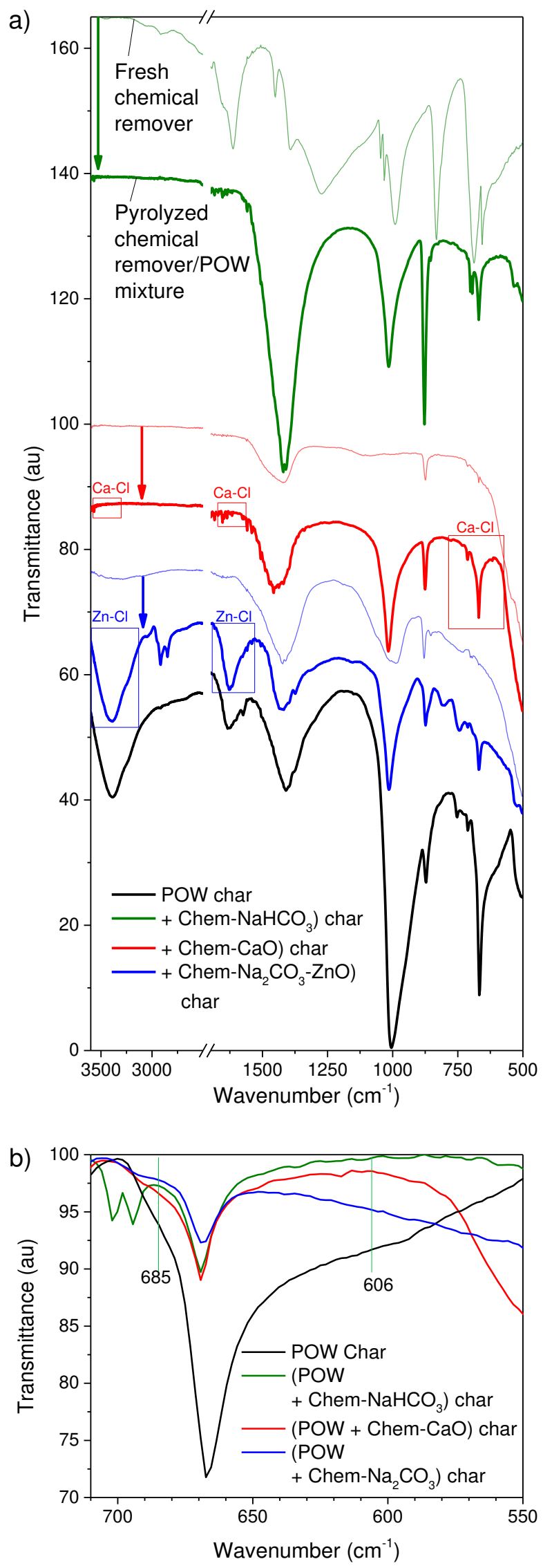
Figure 5 a) FTIR spectra for fresh chemical removers (without POW) and chars of mixtures after pyrolysis at $480{ }^{\circ} \mathrm{C}$ in the batch reactor; b) Zoom of the FTIR $710-550 \mathrm{~cm}^{-1}$ region of pyrolyzed mixtures. Lines in b) at 606 and $685 \mathrm{~cm}^{-1}$ represent the theoretical position of the $\mathrm{C}-\mathrm{Cl}$ stretching in the $-\mathrm{CHCl}-$ groups.

\subsection{HCl adsorption by hot filters from the pyrolysis of POW}

Compacts of adsorbents (Ads- $\mathrm{Al}_{2} \mathrm{O}_{3}-1$, Ads- $\mathrm{Al}_{2} \mathrm{O}_{3}-2$ and Ads- $\mathrm{NaX}$ ) and Chem- $\mathrm{Na}_{2} \mathrm{CO}_{3}-\mathrm{ZnO}$ were used in hot filters allocated in the reactor exit. During the pyrolysis at $480{ }^{\circ} \mathrm{C}$, the temperature of the hot filter, which is heat-insulated, reaches $300 \pm 25^{\circ} \mathrm{C}$. After an experiment, char, adsorbent and condensed pyrolytic oils were collected and their masses are given in Table 4. Firstly, the state of the oils after pyrolysis is striking. Some pyrolytic oils formed a waxy product after cooling at RT ("Sol." in the table) due to higher content of olefins and paraffins with higher carbon numbers as will be discussed in Section 3.4. All the materials, and especially the one based on zeolites, Ads-NaX, yielded lower amounts of oil ( $Y_{\text {Oil }}$ in the range: $33.5-61.0$ wt. \%) than that obtained in the conventional process $(70.4$ wt. \%). Other zeolite catalysts, such as ZSM-5 zeolite, have been shown to modify the product distribution in the pyrolysis of plastic packaging waste, resulting in lower oil yields in favor of increased gas formation [14].

Table 4. Masses of POW, adsorbents and products obtained after pyrolysis at $480{ }^{\circ} \mathrm{C}$.

\begin{tabular}{|l|c|c|c|c|c|c|c|c|c|}
\hline & \multicolumn{2}{|c|}{ Initial } & \multicolumn{9}{c|}{ After pyrolysis } \\
\hline & $\begin{array}{c}\text { POW } \\
(\mathrm{g})\end{array}$ & $\begin{array}{c}\text { Adsorbent } \\
(\mathrm{g})\end{array}$ & $\begin{array}{c}\text { Char } \\
(\mathrm{g})\end{array}$ & $\begin{array}{c}\text { Wt. loss } \\
(\%)\end{array}$ & $\begin{array}{c}\text { Adsorbent } \\
(\mathrm{g})\end{array}$ & $\begin{array}{c}\text { Oil } \\
(\mathrm{g})\end{array}$ & $\begin{array}{c}Y_{\text {Oil }}^{\mathrm{b}} \\
(\mathrm{wt} . \%)\end{array}$ & $\begin{array}{c}\text { Oil } \\
(\mathrm{ml})\end{array}$ & $\begin{array}{c}\text { Oil } \\
(\text { state })\end{array}$ \\
\hline $\mathrm{POW}$ & 19.9 & - & 0.7 & 96.5 & - & 14.0 & 70.4 & 16.0 & Liq. \\
\hline$+\mathrm{Ads}-\mathrm{Al}_{2} \mathrm{O}_{3}-1$ & 20.0 & 15.0 & 0.8 & 96.0 & 16.5 & 9.5 & 47.5 & 10.0 & Sol. \\
\hline$+\mathrm{Ads}-\mathrm{Al}_{2} \mathrm{O}_{3}-2$ & 20.0 & 15.0 & 0.8 & 96.0 & 14.3 & 12.2 & 61.0 & 14.0 & Sol. \\
\hline$+\mathrm{Ads}-\mathrm{NaX}$ & 20.0 & 15.0 & 0.6 & 97.0 & 20.9 & 6.7 & 33.5 & 7.0 & Sol. \\
\hline$+\mathrm{Chem}-\mathrm{Na}_{2} \mathrm{CO}_{3}-\mathrm{ZnO}$ & 20.0 & 15.0 & 1.4 & 93.0 & 19.1 & 8.1 & 40.5 & 9.5 & Liq. \\
\hline
\end{tabular}


ESEM images of the adsorbents after use in the hot filter are shown in Figure 6, while the chlorine distributions of their respective surfaces performed by ESEM-EDS mapping are shown in Figure 7. Images of these adsorbents before use can be found elsewhere [40]. Chem$\mathrm{Na}_{2} \mathrm{CO}_{3}-\mathrm{ZnO}$ and Ads- $\mathrm{NaX}$ showed the presence of carbon on the surface of some particles, perhaps due to the decomposition of condensable products from the pyrolysis of POW. The chlorine distribution was completely homogenous on the surface of the four adsorbents. Moreover, the materials in the hot filters resulted in chlorine removal in the following order (Table 5): Ads- $\mathrm{NaX}>$ Ads- $\mathrm{Al}_{2} \mathrm{O}_{3}-2>$ Ads- $\mathrm{Al}_{2} \mathrm{O}_{3}-1>$ Chem- $\mathrm{Na}_{2} \mathrm{CO}_{3}-\mathrm{ZnO}$. Ads-NaX showed $65.6 \% \mathrm{Cl}$ retention without considering the amount that retained in char (not pyrolyzed). As seen in the previous section, a significant part of inorganic chlorine (around $4.3 \mathrm{wt} \%$, see Table 3) remains in the char inside the reactor. Chem- $\mathrm{Na}_{2} \mathrm{CO}_{3}-\mathrm{ZnO}$, which offered the best performance of the chemical removers used in direct contact with the waste during pyrolysis (see the previous section), exhibited the worst chlorine retention as a hot filter (23.8 vs. 14.1 $\%)$. The lower retention could be due to the size of this chemical in both configurations. For its use inside the batch reactor it was fine powdered enhancing solid-solid contact and subsequent solid- $\mathrm{HCl}$ contact, while for the hot filter tests it was used in spheres (see Figure 6). Likewise, part of the $\mathrm{HCl}$ released from the POW could not be contacting the chemical remover and freely leaving the reactor, which would occur to a lesser extent in the hot filter configuration. Experiments using powdered adsorbents in the hot filter, as a fixed bed, produced high pressure drops, preventing the passage of the exhaust gas and favoring its condensation until blocking it by compaction. 


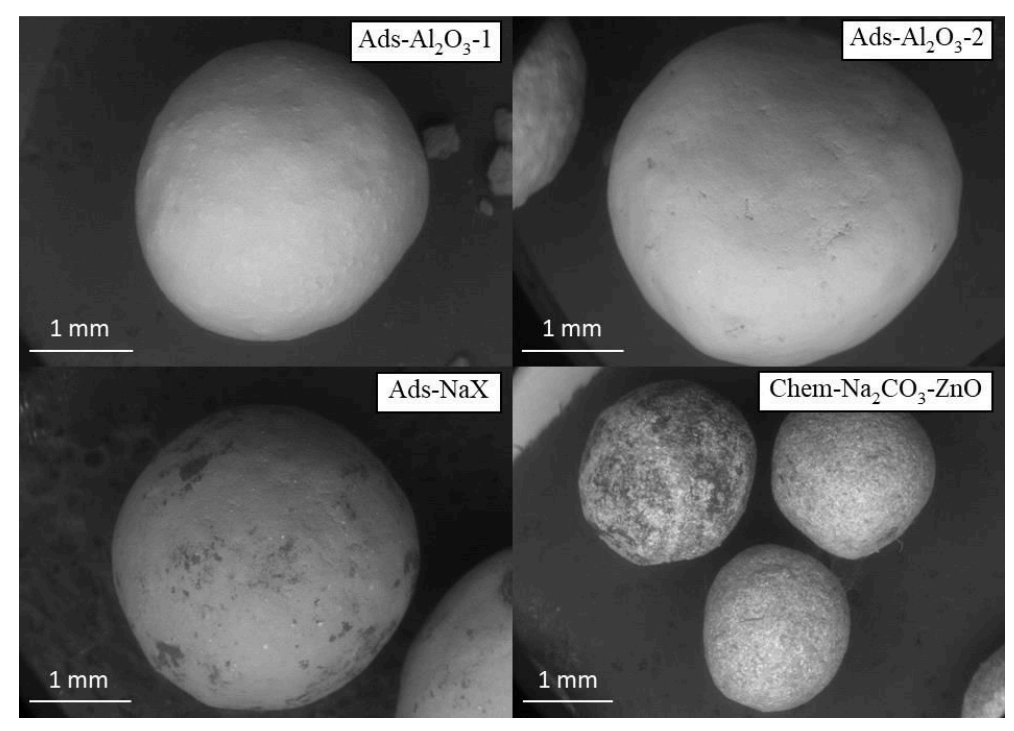

Figure 6 ESEM images of Chem- $\mathrm{Na}_{2} \mathrm{CO}_{3}-\mathrm{ZnO}$, Ads- $\mathrm{NaX}$, Ads- $\mathrm{Al}_{2} \mathrm{O}_{3}-2$ and Ads- $\mathrm{Al}_{2} \mathrm{O}_{3}-1$ after use as a hot filter.

a)
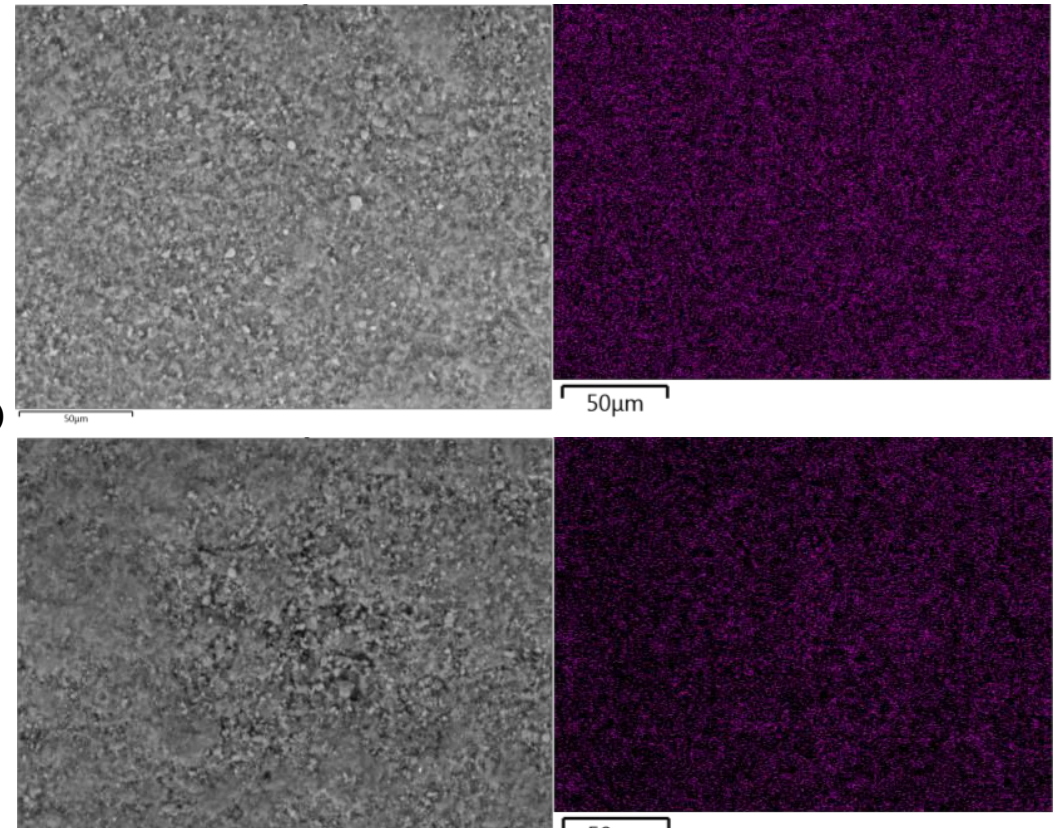

b)

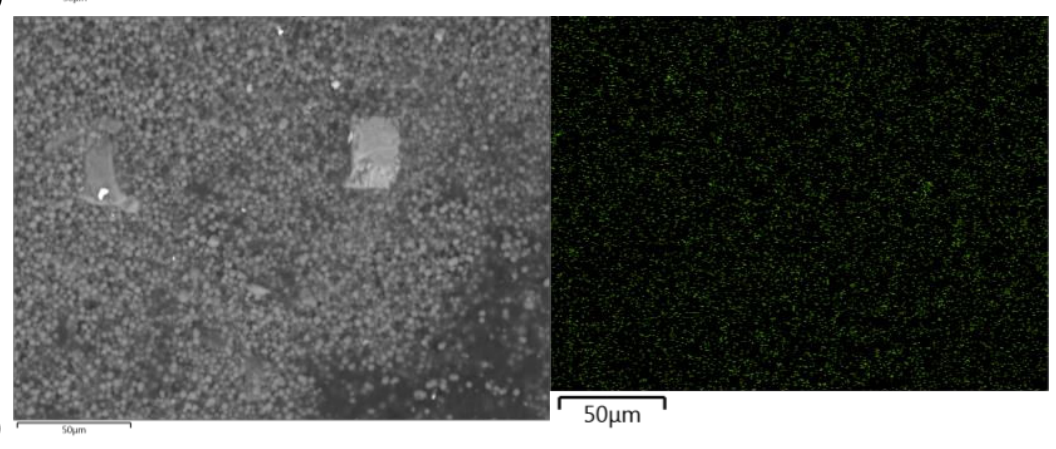


d)

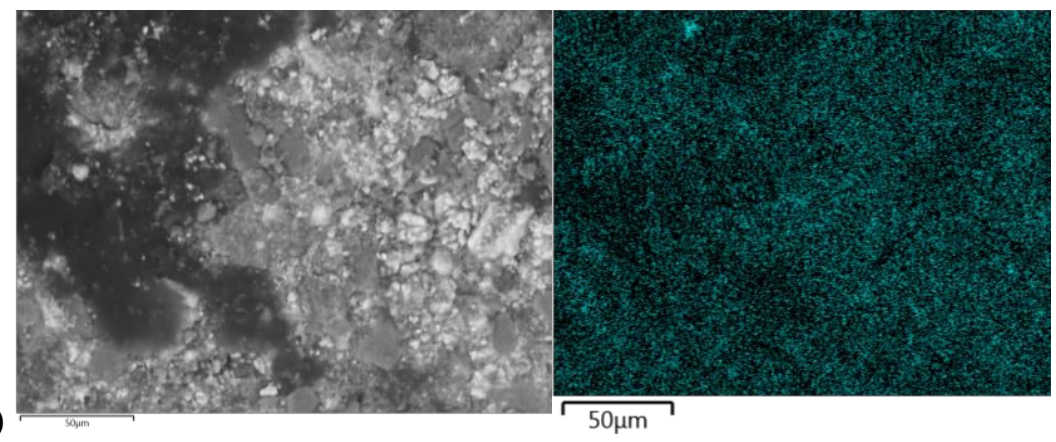

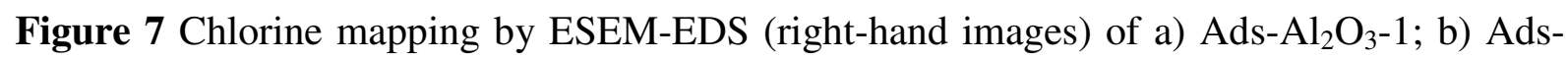
$\mathrm{Al}_{2} \mathrm{O}_{3}-2$; c) Ads-NaX; and d) Chem- $\mathrm{Na}_{2} \mathrm{CO}_{3}-\mathrm{ZnO}$, after their use as a hot filter.

Table 5. Chlorine retention calculated as the percentage of chlorine content loss between that calculated in the hot filter after use and that in the as-received POW according Equation 1.

\begin{tabular}{|c|c|c|}
\hline & $\begin{array}{c}\text { Hot filter after } \\
\text { use }(\mathrm{g})\end{array}$ & $\begin{array}{l}\mathrm{Cl} \text { retention } \\
\text { (wt. \%) }\end{array}$ \\
\hline Ads- $\mathrm{Al}_{2} \mathrm{O}_{3}-1$ & 16.5 & 24.8 \\
\hline Ads- $\mathrm{Al}_{2} \mathrm{O}_{3}-2$ & 14.3 & 34.6 \\
\hline Ads-NaX & 20.9 & 65.6 \\
\hline Chem- $\mathrm{Na}_{2} \mathrm{CO}_{3}-\mathrm{ZnO}$ & 19.2 & 14.1 \\
\hline
\end{tabular}

$*=$ Chlorine measured by ESEM-EDS for hot filters after use in the pyrolysis of POW at $480^{\circ} \mathrm{C}\left(300 \pm 25^{\circ} \mathrm{C}\right.$ in the hot filter).

\subsection{Characterization of pyrolytic oils}

Pyrolytic oils were analysed by FTIR, GC-MS and HPLC-RI to determine their composition and identify any catalytic effect from the use of chemical removers and adsorbents. Initially, a different appearance between oils in terms of colour and state at room temperature was evident at first glance as can be seen in Figure 8. Only the pyrolytic oils obtained without using chemical removers or adsorbents and that from the use of Chem- $\mathrm{Na}_{2} \mathrm{CO}_{3}-\mathrm{ZnO}$ as a hot filter of the exit gases were liquid products at room temperature. Both changed from yellowish to brownish colour over time due to the oxidation with ambient air. The rest of the pyrolytic oils were waxy at room temperature due to higher content of hydrocarbons with a high carbon number and a higher degree of branching. 


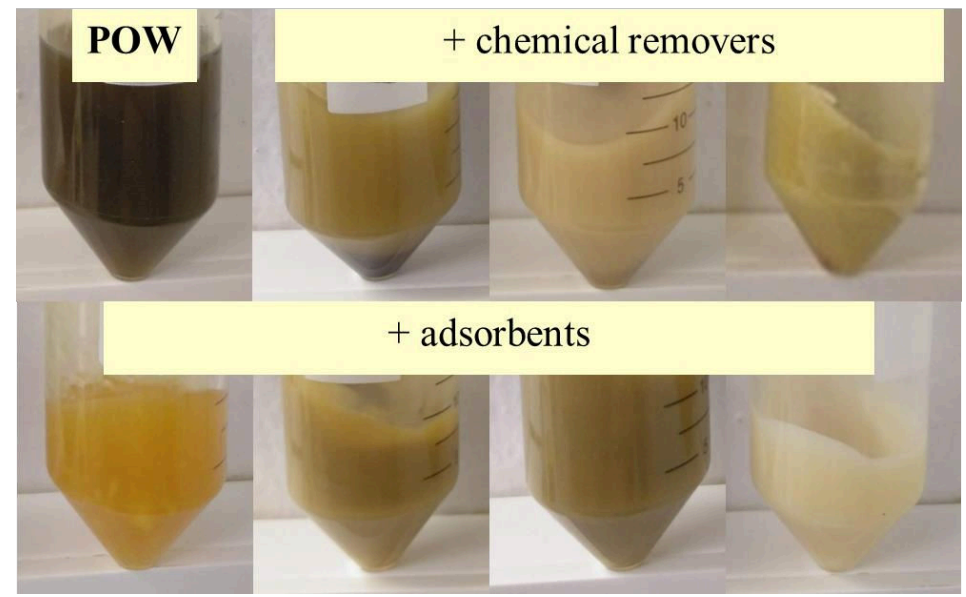

Figure 8 Photographs of pyrolytic oils using chemical removers inside of the batch reactor (top) and as adsorbents in the hot filter (bottom).

FTIR analysis showed similar profiles indicating a similar chemical composition where hydrocarbon related adsorption bands are clearly prominent (see Figure 9). Differences between profiles were minimal, which mainly exhibited the presence of paraffinic compounds identified from recognisable $-\mathrm{CH}_{2}-$ and terminal $-\mathrm{CH}_{3}$ groups. Two large peaks at 2851 and $2920 \mathrm{~cm}^{-1}$ corresponded to the stretching of the $\mathrm{C}-\mathrm{H}$ bonds in the methylene groups [56]. Indeed, the skeletal vibration of these groups gave rise to the double peak appearing at 721 $\mathrm{cm}^{-1}$. The $-\mathrm{CH}_{3}$ vibrations resulted in the band centred at $2956 \mathrm{~cm}^{-1}$, and it is higher as the branching of the chains in the sample is higher. At 1377 and $1460 \mathrm{~cm}^{-1}$ bands relating to the deformation vibrations of the ethyl and methylene groups (alkyl chains) are evident. In addition, there are also bands relating to olefins with a small double peak around 1641-1651 $\mathrm{cm}^{-1}$ due to the stretching of $\mathrm{C}=\mathrm{C}$ bonds, bands at 908 and $993 \mathrm{~cm}^{-1}$ from the $\mathrm{R}-\mathrm{CH}=\mathrm{CH}_{2}$ group, at $964 \mathrm{~cm}^{-1}$ from the trans $-\mathrm{CH}=\mathrm{CH}-$ group, and at $887 \mathrm{~cm}^{-1}$ from the $\mathrm{R}_{1} \mathrm{R}_{2} \mathrm{C}=\mathrm{CH}_{2}$ group [56]. Finally, a small band around $698 \mathrm{~cm}^{-1}$ was assigned to the out-of-plane $=\mathrm{C}-\mathrm{H}$ bending vibration in the aromatics $[42,43]$. 


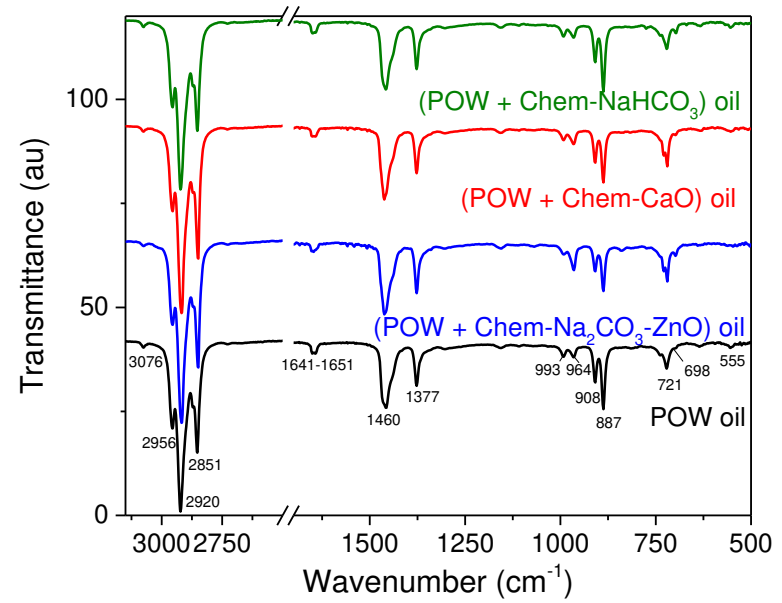

a)

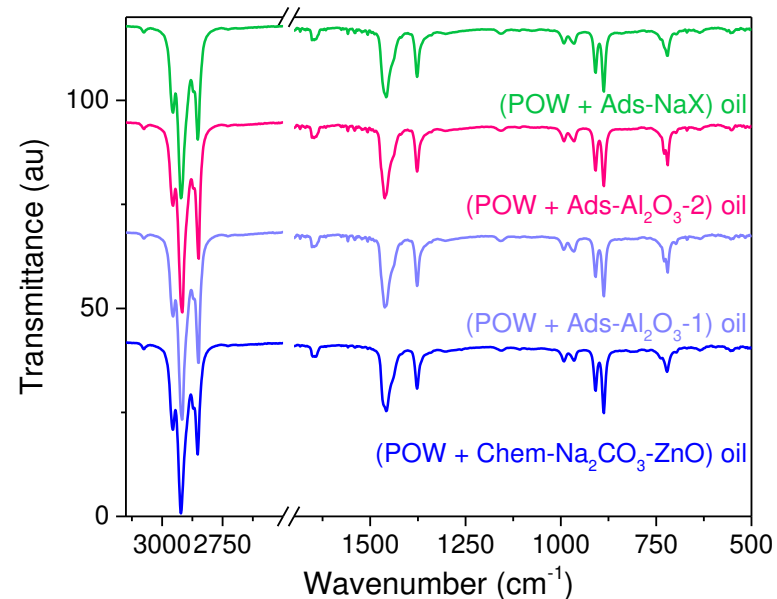

b)

Figure 9 FTIR spectra for pyrolytic oils obtained using a) chemical removers inside the batch reactor and b) as adsorbents in hot filters.

As expected for a polyolefin feedstock, pyrolytic oils obtained in the presence of chemical removers and adsorbents contained a low concentration of aromatics determined from HPLCRI (Figure 10a and 10b, respectively). The aromatic fraction of the pyrolytic oils, after dissolving in n-heptane, was separated following the ASTM D6379-11 method according to the number of rings: saturates, monoaromatics (1 ring), diaromatics (2) and polyaromatics $(3+)$ (these are indicated in Figure 10a-b). Due to the low aromatic content (estimated to be less than 3 wt. \%), the saturated signal overlaps with that of the different types of compounds. Despite this, Chem- $\mathrm{Na}_{2} \mathrm{CO}_{3}-\mathrm{ZnO}$ and $\mathrm{Chem}-\mathrm{NaHCO}_{3}$ showed the highest amount of aromatics (especially mono- and diaromatics) when used as additives in the reaction medium. However, the use of Chem-CaO does seem to slightly increase the aromatic content in the corresponding pyrolytic oil. When adsorbents were used in hot filters, Ads-NaX influenced the production of monoaromatics while $\mathrm{Ads}-\mathrm{Al}_{2} \mathrm{O}_{3}-1$ resulted in aromatics of more than one ring. Ads- $\mathrm{Al}_{2} \mathrm{O}_{3}-2$ showed an intermediate behaviour. Here, Chem- $\mathrm{Na}_{2} \mathrm{CO}_{3}-\mathrm{ZnO}$ when used in a hot filter gave the lowest variation in the composition of the oil when compared to the oil obtained without the use of chemical removers or adsorbents. 
The FTIR and HPLC results are supported by those obtained by GC-MS (Figure 9c-d). It was observed that the samples contain more compounds of high carbon number when chemical removers or adsorbents are used. This is easier to see if the GC-MS profiles of pyrolytic oils are considered, and more specifically the representation of their accumulated RI response values (see Figure 9e-f). In general, the use of a chlorine retention material increases the amount of branched hydrocarbons and with greater carbon number in the pyrolytic oil (preventing them from being completely liquid at room temperature), except when Chem$\mathrm{Na}_{2} \mathrm{CO}_{3}-\mathrm{ZnO}$ is used as a hot filter. For this remover, condensed oil was obtained in the hot filter together with the remover which would explain its low chlorine retention when used in this configuration (14.1 wt. \%; see Table 5). According to the GC-MS results, pyrolytic oils are olefinic and aliphatic hydrocarbons ranging from $\mathrm{C}_{7}$ to $\mathrm{C}_{40}$. POW oil showed a wide distribution of triplet peaks in the chromatogram, attributed to dienes, alkenes (olefins), and alkanes (paraffins) with a specific carbon number. In less abundance are a series of branched compounds, as well as alkyl aldehydes, which in the spectra. These homologues series of saturated and unsaturated hydrocarbons in oils derived from polyolefins are formed from random scissions of the chains of the starting PE and PP [57]. The chain scission results in alkanes and the large formation of $\mathrm{C}=\mathrm{C}$ bonds motivated by the stabilization of the radicals generated [58]. On the other hand, as PVC accounted for only $1.5 \mathrm{wt} . \%$ in POW, the share of its pyrolysis products are barely appreciable. 

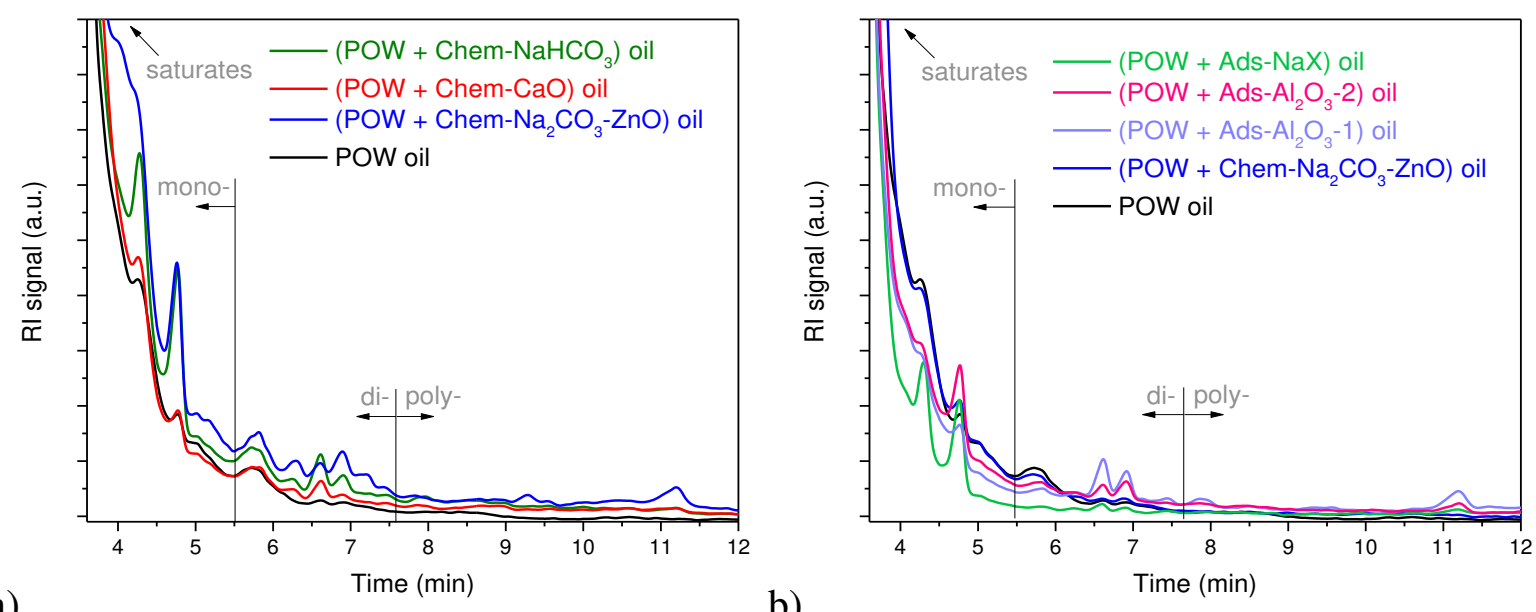

a)

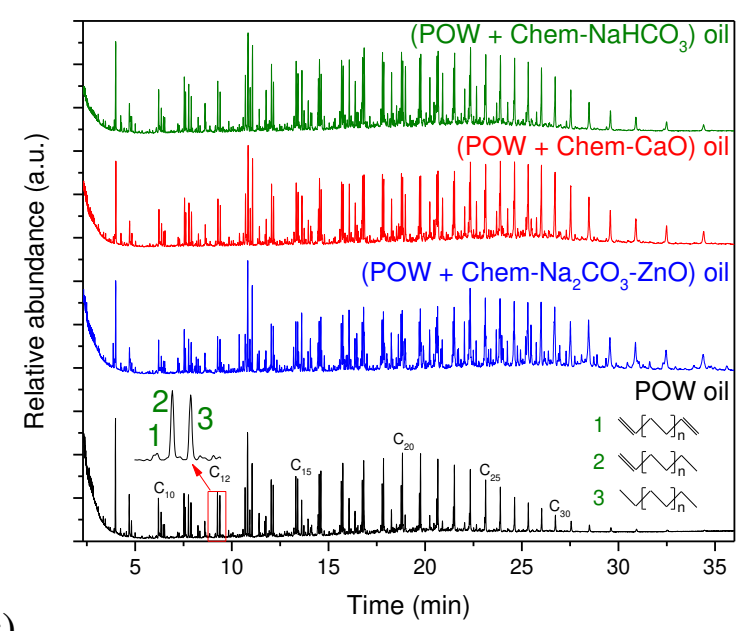

c)

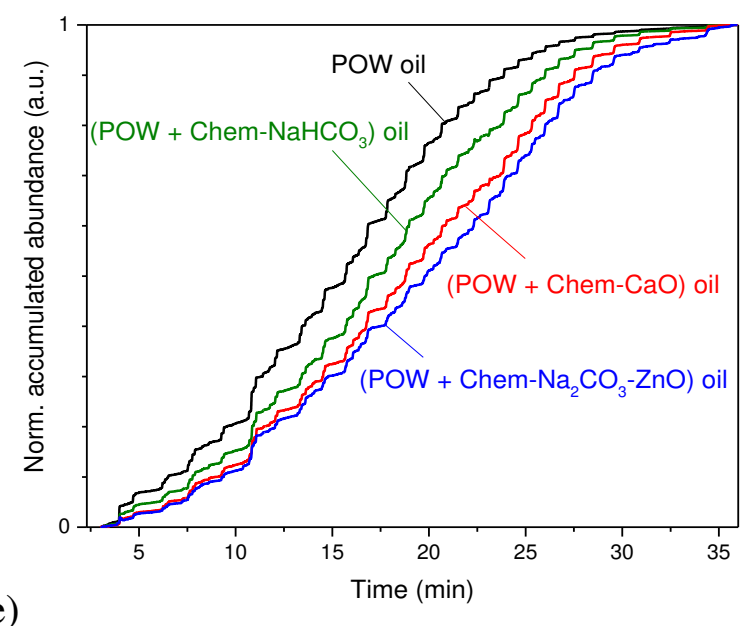

b)

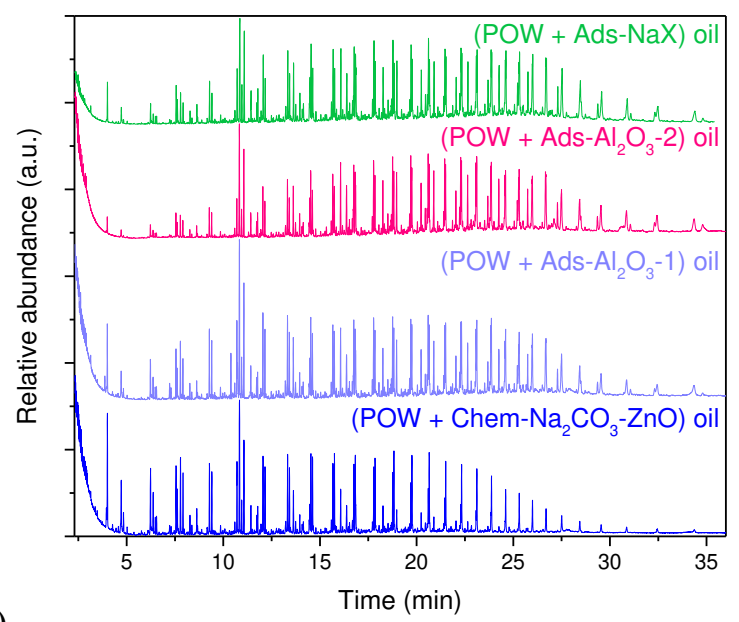

d)

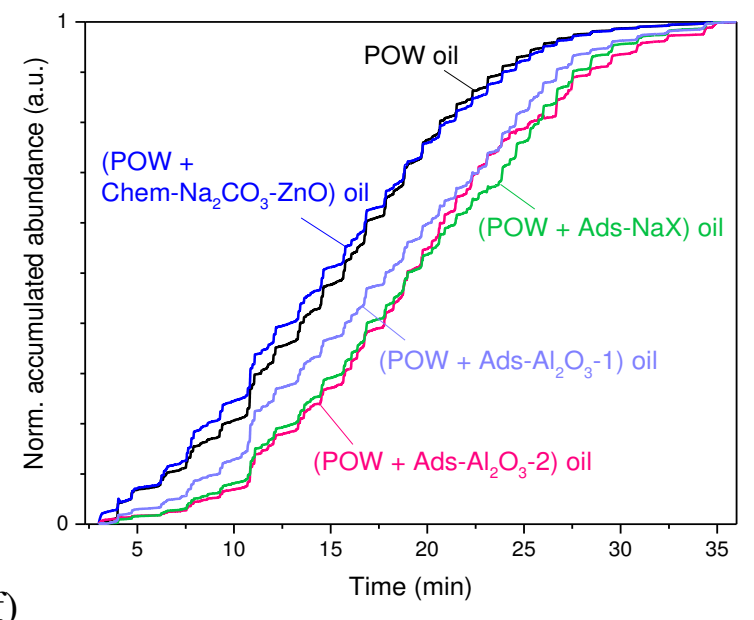

Figure 10 HPLC-RI of pyrolytic oils obtained using a) chemical removers inside the batch reactor and b) as adsorbents in hot filters. GC-MS profiles of pyrolytic oils obtained from c) chemical removers inside the batch reactor and d) as adsorbents in hot filters. e-f) Accumulated abundance from GC-MS profiles. 


\section{Conclusions}

The behaviour of different materials for the retention of chlorine originating from the pyrolysis of urban chlorine-containing polyolefin waste (98.5 wt. \% polyolefins) was studied in a semi-batch reactor. Chemical removers based on $\mathrm{NaHCO}_{3}, \mathrm{CaO}$ and $\mathrm{Na}_{2} \mathrm{CO}_{3}-\mathrm{ZnO}$ and adsorbents $\left(\mathrm{Al}_{2} \mathrm{O}_{3}\right.$ and $\mathrm{NaX}$ zeolites $)$ were tested for chlorine removal. These materials were mixed with POW, or separately in the hot filters $\left(300 \pm 20^{\circ} \mathrm{C}\right)$ during the pyrolysis at $480{ }^{\circ} \mathrm{C}$. Chem- $\mathrm{Na}_{2} \mathrm{CO}_{3}-\mathrm{ZnO}$ gave the highest chlorine retention (23.8 wt. \%) when used as a chemical remover in direct contact with POW according to the char characterization, while $\mathrm{NaX}$ zeolites gave the best performance $(65.6 \mathrm{wt} . \%)$ as a hot filter, when in contact with the pyrolysis vapour in the exit gas stream. In addition to Ads- $\mathrm{NaX}, \mathrm{Al}_{2} \mathrm{O}_{3}$-based adsorbents also showed better performances in the retention of chlorine (between 25-36 wt. \%) than those exhibited by any chemical remover. Despite having larger particle sizes, the solid/gas contact in the adsorbents seems to be more effective in the hot filter configuration. On the other hand, the chemical remover that retained the most chlorine when used inside the reactor (Chem$\mathrm{Na}_{2} \mathrm{CO}_{3}-\mathrm{ZnO}$ ), showed the lowest chlorine retention when it was tested as a hot filter after extrusion-spheronization (only $14.1 \mathrm{wt} \%$ ). The pyrolytic liquids obtained (densities in the range: $0.85-0.96 \mathrm{~g} / \mathrm{cm}^{3}$ ) consisted of $\mathrm{C}_{7}-\mathrm{C}_{40}$ hydrocarbon mixtures containing olefinic and aliphatic hydrocarbons and very small quantities of aromatics (quantities being dependent on the chlorine retention material used, and below $3 \mathrm{wt}$ \% according to HPLC characterization). Chem- $\mathrm{Na}_{2} \mathrm{CO}_{3}-\mathrm{ZnO}$ and $\mathrm{Chem}-\mathrm{NaHCO}_{3}$ showed the highest amount of aromatics (especially mono- and diaromatics) when used as additives in the reaction medium. When adsorbents were used in hot filters, Ads- $\mathrm{NaX}$ influenced the production of monoaromatics while $\mathrm{Al}_{2} \mathrm{O}_{3}$ based adsorbents resulted in aromatics of more than one ring. In a hot filter, Chem- $\mathrm{Na}_{2} \mathrm{CO}_{3}-$ $\mathrm{ZnO}$ gave the lowest variation in composition of the oil when compared to the oil obtained without the use of chemical removers or adsorbents. Consequently, its resulting pyrolytic oil 
was completely liquid, as in the case of pyrolyzing POW only. In the rest of cases, the chlorine removal processes resulted in waxier pyrolytic oils having a higher carbon number and higher degree of branching.

\section{Acknowledgement}

The funding to support this research was awarded by Innovate UK Energy Catalyst 4. D.T. is thankful for his contract funded by this Project. D.A.S.M and RT are thankful for the H2020 SME Innovation Programme and the European Commission for training in industrial innovation management. Cranfield University thanks the technical assistance received from the Recycling Technologies Ltd company throughout the project.

\section{References}

[1] Banning single-use plastic: lessons and experiences from countries, in: Book Banning single-use plastic: lessons and experiences from countries, United Nations Environment report, 2018.

[2] A. Marongiu, T. Faravelli, G. Bozzano, M. Dente, E. Ranzi, Thermal degradation of poly(vinyl chloride), J. Anal. Appl. Pyrolysis, 70 (2003) 519-553.

[3] S.D. Anuar Sharuddin, F. Abnisa, W.M.A. Wan Daud, M.K. Aroua, A review on pyrolysis of plastic wastes, Energy Convers. Manag., 115 (2016) 308-326.

[4] R. Geyer, J.R. Jambeck, K.L. Law, Production, use, and fate of all plastics ever made, Sci. Adv., 3 (2017) e1700782.

[5] N. Lingaiah, M.A. Uddin, A. Muto, T. Imai, Y. Sakata, Removal of organic chlorine compounds by catalytic dehydrochlorination for the refinement of municipal waste plastic derived oil, Fuel, 80 (2001) 1901-1905. 
[6] M.A. Keane, Catalytic conversion of waste plastics: focus on waste PVC, J. Chem. Technol. Biotechnol., 82 (2007) 787-795.

[7] J. Yu, L. Sun, C. Ma, Y. Qiao, H. Yao, Thermal degradation of PVC: A review, Waste Manage., 48 (2016) 300-314.

[8] K.-B. Park, S.-J. Oh, G. Begum, J.-S. Kim, Production of clean oil with low levels of chlorine and olefins in a continuous two-stage pyrolysis of a mixture of waste low-density polyethylene and polyvinyl chloride, Energy, 157 (2018) 402-411.

[9] T. Bhaskar, R. Negoro, A. Muto, Y. Sakata, Prevention of chlorinated hydrocarbons formation during pyrolysis of PVC or PVDC mixed plastics, Green Chem., 8 (2006) 697-700. [10] H. Bockhorn, J. Hentschel, A. Hornung, U. Hornung, Environmental engineering: Stepwise pyrolysis of plastic waste, Chem. Eng. Sci., 54 (1999) 3043-3051.

[11] N. Sophonrat, L. Sandström, R. Svanberg, T. Han, S. Dvinskikh, C.M. Lousada, W. Yang, Ex Situ Catalytic Pyrolysis of a Mixture of Polyvinyl Chloride and Cellulose Using Calcium Oxide for $\mathrm{HCl}$ Adsorption and Catalytic Reforming of the Pyrolysis Products, Ind. Eng. Chem. Res., 58 (2019) 13960-13970.

[12] S.L. Wong, N. Ngadi, T.A.T. Abdullah, I.M. Inuwa, Current state and future prospects of plastic waste as source of fuel: A review, Renew. Sust. Energ. Rev., 50 (2015) 1167-1180.

[13] B. Han, Y. Chen, Y. Wu, D. Hua, Z. Chen, W. Feng, M. Yang, Q. Xie, Co-pyrolysis behaviors and kinetics of plastics-biomass blends through thermogravimetric analysis, J. Therm. Anal. Calorim., 115 (2014) 227-235.

[14] A. Lopez-Urionabarrenechea, I. de Marco, B.M. Caballero, M.F. Laresgoiti, A. Adrados, Catalytic stepwise pyrolysis of packaging plastic waste, J. Anal. Appl. Pyrolysis, 96 (2012) 54-62. 
[15] M. Blazsó, E. Jakab, Effect of metals, metal oxides, and carboxylates on the thermal decomposition processes of poly (vinyl chloride), J. Anal. Appl. Pyrolysis, 49 (1999) 125143.

[16] M.F. Ali, M.N. Siddiqui, Thermal and catalytic decomposition behavior of PVC mixed plastic waste with petroleum residue, J. Anal. Appl. Pyrolysis, 74 (2005) 282-289.

[17] H. Kuramochi, D. Nakajima, S. Goto, K. Sugita, W. Wu, K. Kawamoto, HCl emission during co-pyrolysis of demolition wood with a small amount of PVC film and the effect of wood constituents on $\mathrm{HCl}$ emission reduction, Fuel, 87 (2008) 3155-3157.

[18] A. López, I. de Marco, B.M. Caballero, M.F. Laresgoiti, A. Adrados, Dechlorination of fuels in pyrolysis of PVC containing plastic wastes, Fuel Process. Technol., 92 (2011) 253260.

[19] A. Lopez-Urionabarrenechea, I. de Marco, B.M. Caballero, M.F. Laresgoiti, A. Adrados, Upgrading of chlorinated oils coming from pyrolysis of plastic waste, Fuel Process. Technol., 137 (2015) 229-239.

[20] M. Brebu, T. Bhaskar, K. Murai, A. Muto, Y. Sakata, M.A. Uddin, Removal of nitrogen, bromine, and chlorine from PP/PE/PS/PVC/ABS-Br pyrolysis liquid products using Fe- and Ca-based catalysts, Polym. Degrad. Stab., 87 (2005) 225-230.

[21] S.M. Al-Salem, A. Antelava, A. Constantinou, G. Manos, A. Dutta, A review on thermal and catalytic pyrolysis of plastic solid waste (PSW), J. Environ. Manage., 197 (2017) 177 198.

[22] A. Veksha, A. Giannis, W.-D. Oh, V.W.C. Chang, G. Lisak, Upgrading of noncondensable pyrolysis gas from mixed plastics through catalytic decomposition and dechlorination, Fuel Process. Technol., 170 (2018) 13-20. 
[23] B. Fekhar, L. Gombor, N. Miskolczi, Pyrolysis of chlorine contaminated municipal plastic waste: In-situ upgrading of pyrolysis oils by Ni/ZSM-5, Ni/SAPO-11, red mud and $\mathrm{Ca}(\mathrm{OH}) 2$ containing catalysts, J. Energy Inst., 92 (2019) 1270-1283.

[24] M.-H. Cho, S.-H. Jung, J.-S. Kim, Pyrolysis of Mixed Plastic Wastes for the Recovery of Benzene, Toluene, and Xylene (BTX) Aromatics in a Fluidized Bed and Chlorine Removal by Applying Various Additives, Energy Fuels, 24 (2010) 1389-1395.

[25] M. Daoudi, J.K. Walters, The reaction of $\mathrm{HCl}$ gas with calcined commercial limestone particles: The effect of particle size, Chem. Eng. J., 47 (1991) 11-16.

[26] W. Wang, Z. Ye, I. Bjerle, The kinetics of the reaction of hydrogen chloride with fresh and spent Ca-based desulfurization sorbents, Fuel, 75 (1996) 207-212.

[27] W. Kaminsky, J.-S. Kim, Pyrolysis of mixed plastics into aromatics, J. Anal. Appl. Pyrolysis, 51 (1999) 127-134.

[28] M. Li, H. Shaw, C.-L. Yang, Reaction Kinetics of Hydrogen Chloride with Calcium Oxide by Fourier Transform Infrared Spectroscopy, Ind. Eng. Chem. Res., 39 (2000) 18981902.

[29] Y. Masuda, T. Uda, O. Terakado, M. Hirasawa, Pyrolysis study of poly(vinyl chloride)metal oxide mixtures: Quantitative product analysis and the chlorine fixing ability of metal oxides, J. Anal. Appl. Pyrolysis, 77 (2006) 159-168.

[30] K.-Y. Chiang, J.-C. Jih, K.-L. Lin, The effects of calcium hydroxide on hydrogen chloride emission characteristics during a simulated densified refuse-derived fuel combustion process, J. Hazard. Mater., 157 (2008) 170-178.

[31] T. Kameda, N. Uchiyama, K.-S. Park, G. Grause, T. Yoshioka, Removal of hydrogen chloride from gaseous streams using magnesium-aluminum oxide, Chemosphere, 73 (2008) 844-847. 
[32] H.M. Zhu, X.G. Jiang, J.H. Yan, Y. Chi, K.F. Cen, TG-FTIR analysis of PVC thermal degradation and $\mathrm{HCl}$ removal, J. Anal. Appl. Pyrolysis, 82 (2008) 1-9.

[33] C.-S. Chyang, Y.-L. Han, Z.-C. Zhong, Study of $\mathrm{HCl}$ Absorption by $\mathrm{CaO}$ at High Temperature, Energy Fuels, 23 (2009) 3948-3953.

[34] C.-S. Chyang, Y.-L. Han, L.-W. Wu, H.-P. Wan, H.-T. Lee, Y.-H. Chang, An investigation on pollutant emissions from co-firing of RDF and coal, Waste Manage., 30 (2010) 1334-1340.

[35] Z. Sun, F.-C. Yu, F. Li, S. Li, L.-S. Fan, Experimental Study of HCl Capture Using CaO Sorbents: Activation, Deactivation, Reactivation, and Ionic Transfer Mechanism, Ind. Eng. Chem. Res., 50 (2011) 6034-6043.

[36] S. Pachitsas, L. Skaarup Jensen, S. Wedel, J. Boll Illerup, K. Dam-Johansen, Hydrogen chloride $(\mathrm{HCl})$ absorption by raw meal and raw meal compounds, using in-situ $\mathrm{HCl}$ generation and TGA-FTIR tests, J. Environ. Chem. Eng., 7 (2019) 102869.

[37] G. Lopez, M. Artetxe, M. Amutio, J. Bilbao, M. Olazar, Thermochemical routes for the valorization of waste polyolefinic plastics to produce fuels and chemicals. A review, Renew. Sust. Energ. Rev., 73 (2017) 346-368.

[38] B.K. Sharma, B.R. Moser, K.E. Vermillion, K.M. Doll, N. Rajagopalan, Production, characterization and fuel properties of alternative diesel fuel from pyrolysis of waste plastic grocery bags, Fuel Process. Technol., 122 (2014) 79-90.

[39] B. Kunwar, H.N. Cheng, S.R. Chandrashekaran, B.K. Sharma, Plastics to fuel: a review, Renew. Sust. Energ. Rev., 54 (2016) 421-428.

[40] D. Torres, Y. Jiang, D.A. Sanchez-Monsalve, G.A. Leeke, Hydrochloric acid removal from the thermogravimetric pyrolysis of PVC, J. Anal. Appl. Pyrolysis, 149 (2020) 104831. 
[41] J. Zhou, B. Gui, Y. Qiao, J. Zhang, W. Wang, H. Yao, Y. Yu, M. Xu, Understanding the pyrolysis mechanism of polyvinylchloride (PVC) by characterizing the chars produced in a wire-mesh reactor, Fuel, 166 (2016) 526-532.

[42] M. Theodorou, B. Jasse, Fourier-transform infrared study of conformational changes in plasticized poly(vinyl chloride), J. Polym. Sci. Pol. Phys., 21 (1983) 2263-2274.

[43] E. Pretsch, P. Bühlmann, M. Badertscher, Structure Determination of Organic Compounds. Tables of Spectral Data, Springer-Verlag Berlin Heidelberg, 2009.

[44] M.S. Abbas-Abadi, M.N. Haghighi, H. Yeganeh, A.G. McDonald, Evaluation of pyrolysis process parameters on polypropylene degradation products, J. Anal. Appl. Pyrolysis, 109 (2014) 272-277.

[45] J.N. Hahladakis, C.A. Velis, R. Weber, E. Iacovidou, P. Purnell, An overview of chemical additives present in plastics: Migration, release, fate and environmental impact during their use, disposal and recycling, J. Hazard. Mater., 344 (2018) 179-199.

[46] J. Jamradloedluk, C. Lertsatitthanakorn, Characterization and Utilization of Char Derived from Fast Pyrolysis of Plastic Wastes, Procedia Engineering, 69 (2014) 1437-1442.

[47] S. Joshi, S. Kalyanasundaram, V. Balasubramanian, Quantitative Analysis of Sodium Carbonate and Sodium Bicarbonate in Solid Mixtures Using Fourier Transform Infrared Spectroscopy (FT-IR), Appl. Spectrosc., 67 (2013) 841-845.

[48] P. Raizada, P. Shandilya, P. Singh, P. Thakur, Solar light-facilitated oxytetracycline removal from the aqueous phase utilizing a $\mathrm{H} 2 \mathrm{O} 2 / \mathrm{ZnWO} 4 / \mathrm{CaO}$ catalytic system, J. Taibah Univ. Sci., 11 (2017) 689-699.

[49] T. Baird, J.R. Fryer, B. Grant, Carbon formation on iron and nickel foils by hydrocarbon pyrolysis-reactions at $700^{\circ} \mathrm{C}$, Carbon, 12 (1974) 591-602.

[50] S. Hosseini, A. Niaei, S. D., Production of $\gamma-\mathrm{Al}_{2} \mathrm{O}_{3}$ from Kaolin, Open J. Phys. Chem., 1 (2011) 23-27. 
[51] M. Kooti, A. Naghdi Sedeh, Microwave-Assisted Combustion Synthesis of ZnO Nanoparticles, J. Chem., 2013 (2013) 4.

[52] T.N. Tran, T.V. Anh Pham, M.L. Phung Le, T.P. Thoa Nguyen, V.M. Tran, Synthesis of amorphous silica and sulfonic acid functionalized silica used as reinforced phase for polymer electrolyte membrane, Adv. Nat. Sci.-Nanosci., 4 (2013) 045007.

[53] M.Z.M. Noor, N.A. Sollahunddin, S. Irawan, Surface Modification of Aluminium Oxide (A12O3) Nanoparticles (NPs) on Detection of Crude Oil Production, Proceedings, 2 (2018) 1273.

[54] E.K. Tiburu, M. Mutocheluh, P.K. Arthur, P.W. Narkwa, A.A. Salifu, M.A. Agyei, R. Yeboah, H.N.A. Fleischer, J. Zhuang, G. Awandare, Antifungal and Anti-Proliferative Effects of Zeolites A and X on Yeast Pathogenic and Cancer Cells In Vitro, J. Biomater. Tiss. Eng., 7 (2017) 544-555.

[55] F. Iskandar, N.A. Zen, T.R. Mayangsari, A.H. Aimon, A.A. Pramana, Development of faujasite-type zeolite and iron oxide as mixed catalyst for aquathermolysis reaction of heavy oil, Mater. Res. Express, 6 (2019) 045510.

[56] A. Chaala, H. Darmstadt, C. Roy, Vacuum pyrolysis of electric cable wastes, J. Anal. Appl. Pyrolysis, 39 (1997) 79-96.

[57] P. Rutkowski, A. Kubacki, Influence of polystyrene addition to cellulose on chemical structure and properties of bio-oil obtained during pyrolysis, Energy Convers. Manag., 47 (2006) 716-731.

[58] V. Pacáková, P.A. Leclercq, Gas chromatography-mass spectrometry and highperformance liquid chromatographic analyses of thermal degradation products of common plastics, J. Chromatogr., A, 555 (1991) 229-237. 